\title{
Desenvolvimento simultâneo de semigrabens ortogonais e oblíquos à direção de distensão: modelagem física de análogo natural no Nordeste brasileiro
}

\author{
Simultaneous development of semigrabens orthogonal and oblique to the extension \\ direction: physical modeling of natural analogues in Northeastern Brazil
}

\begin{abstract}
André João Palma Conde Blanco ${ }^{1}$, Fernando César Alves da Silva ${ }^{1,2}$, Emanuel Ferraz Jardim de Sá ${ }^{1,2}$
${ }^{1}$ Programa de Pós-graduação em Geodinâmica e Geofísica, Universidade Federal do Rio Grande do Norte - UFRN, Campus Universitário - Lagoa Nova, Caixa Postal 1596, CEP 59078-970, Natal, RN, BR (ablanco@sapo.pt)

${ }^{2}$ Departamento de Geologia, Universidade Federal do Rio Grande do Norte - UFRN, Natal, RN, BR (fernando@geologia.ufrn.br; emanuel@ccet.ufrn.br)
\end{abstract}

Recebido em 31 de maio de 2013; aceito em 30 de outubro de 2013

\begin{abstract}
Resumo
A modelagem física é uma ferramenta cada vez mais usada na geologia para fornecer informação sobre os diversos estágios evolutivos (nucleação, desenvolvimento e geometria) de estruturas geológicas em várias escalas. No caso particular da simulação da tectônica distensional, a modelagem proporciona uma melhor compreensão da geometria e evolução de falhas e da arquitetura tectonoestratigráfica de bacias rifte. Neste trabalho foi utilizado um aparato tipo caixa de areia para estudar a nucleação e o desenvolvimento de bacias influenciadas por estruturas prévias no embasamento, com trend variável em relação à direção de distensão. Para tal, foram realizados dois tipos de experimentos para: (i) simular o desenvolvimento individual (independente) de semigrabens com abertura ortogonal ou oblíqua à direção de distensão; (ii) simular o desenvolvimento simultâneo desses semigrabens ortogonais ou oblíquos à direção de distensão. Em ambos os casos foram utilizados os mesmos materiais analógicos (areia de quartzo e uma mistura de areia e gesso, simulando o material sin e pré-tectônico, respectivamente) bem como foram mantidas as demais condições de contorno. Os resultados obtidos foram comparados com um análogo natural representado pela Bacia do Rio do Peixe (uma das bacias interiores eocretáceas do Nordeste do Brasil). Os modelos permitiram observar o desenvolvimento segmentado das falhas de borda, com geometria lístrica, frequentemente formando rampas de revezamento, além do desenvolvimento de falhas internas às bacias localizadas nas suas porções mais basais, similares àquelas observadas nas seções sísmicas do análogo natural. Os resultados confirmam a influência da herança tectônica do embasamento na geometria dos depocentros rifte.
\end{abstract}

Palavras-chave: Modelagem física; Bacia rifte ortogonal; Bacia rifte oblíqua; Herança do embasamento; Bacia do Rio do Peixe.

\begin{abstract}
The physical modeling tool is being increasingly used in geology to provide information about the evolutionary stages (nucleation, growth and geometry) of geological structures at various scales. In the simulations of extensional tectonics, modeling provides a better understanding of fault geometry and evolution of the tectonic-stratigraphic architecture of rift basins. In this study a sandbox type apparatus was used to study the nucleation and development of basins influenced by previous structures in the basement, variably oriented as regards to the main extensional axis. Two types of experiments were conducted in order to: (i) simulate the individual (independent) development of half-grabens oriented orthogonal or oblique to the extension direction; (ii) simulate the simultaneous development of such half-grabens, orthogonal or oblique to the extension direction. In both cases the same materials (sand mixed with gypsum) were used and the same boundary conditions were maintained. The results were compared with a natural analogue represented by the Rio do Peixe Basin (one of the eocretaceous interior basins of Northeast Brazil). The obtained models allowed to observe the development of segmented border faults with listric geometry, often forming relay ramps, and the development of inner basins faults that affect only the basal strata, like the ones observed in the seismic sections of the natural analogue. The results confirm the importance of basement tectonic heritage in the geometry of rift depocenters.
\end{abstract}

Keywords: Physical modeling; Orthogonal rift basin; Oblique rift basin; Basement heritage; Rio do Peixe Basin. 


\section{INTRODUÇÃO}

A arquitetura de bacias sedimentares, o desenvolvimento de falhas distensionais, a geometria de zonas de transferência e os processos envolvidos na formação dessas estruturas têm despertado uma crescente atenção de pesquisadores, tanto na academia como na indústria de hidrocarbonetos, seja em busca do conhecimento de como e porque tais estruturas se desenvolvem, seja pelos aspectos econômicos, devido ao impacto que o arranjo geométrico das estruturas, sua cinemática e interação com processos sedimentares têm com a migração e o armazenamento de óleo e gás. A aplicação da modelagem física (e/ou numérica), associada às informações de campo, geológicas e geofísicas, tem revelado que essa técnica é uma ferramenta importante no estudo da evolução dessas bacias (Corti et al., 2007).

De forma geral, o estudo de bacias sedimentares demanda o conhecimento do seu embasamento, pois a sua constituição litológica, os contrastes reológicos e o comportamento mecânico podem controlar a geometria das bacias sobrepostas, sua estruturação interna e mesmo os modelos de deposição sedimen$\operatorname{tar}$ (Hall et al., 2012). O desenvolvimento de riftes continentais é largamente influenciado por zonas de fraqueza pré-existentes no embasamento, que quase sempre são representadas por estruturas dúcteis (em especial, zonas de cisalhamento) que são reativadas (ou aproveitadas como um sítio favorável) em nível crustal mais raso. Nesse contexto, a modelagem física tem sido empregada para analisar o papel das estruturas herdadas na nucleação (e na arquitetura interna) de bacias controladas por essas descontinuidades, tais como as dos riftes da Tailândia (Morley et al., 2004), do Leste da África (Corti et al., 2007) e do segmento sudeste da Mid-Polish Trough (Polônia) (Gutowski e Koyi, 2007), bem como no desenvolvimento de zonas de transferência (Acocella et al., 1999; Hus et al., 2005). A depender da orientação relativa entre as estruturas formadas/reativadas (que controlam a geometria dos depocentros) e o eixo de distensão superimposto, as bacias tipo rifte (grabens ou semigrabens) podem ser designadas como de abertura ortogonal ou oblíqua.

A maioria dos trabalhos experimentais publicados analisam bacias de abertura oblíqua ou ortogonal de forma isolada, podendo incluir setores de transição como rampas laterais ou oblíquas. O presente estudo, além de experimentos com bacias isoladas, foca o desenvolvimento simultâneo desses dois tipos de bacias. Em todos os casos simulados, as falhas principais das bacias foram nucleadas em zonas de fraqueza pré-existentes no embasamento. A modelagem das bacias com desenvolvimento simultâneo é comparada com um exemplo natural representado pela Bacia do Rio do Peixe, uma das bacias interiores eocretáceas do Nordeste do Brasil. Essa bacia é composta de sub-bacias (semigrabens de Sousa e Brejo das Freiras) com orientações distintas em função do controle das falhas eocretáceas por zonas de cisalhamento brasilianas, com direções distintas. A bacia do Rio do Peixe foi objeto de estudos, que tiveram a participação dos autores deste texto, no âmbito de um projeto UFRN/Petrobras, abordando as bacias interiores do Nordeste.

\section{AS BACIAS INTERIORES DO NORDESTE DO BRASIL: O EXEMPLO DA BACIA DO RIO DO PEIXE}

As bacias interiores do Nordeste brasileiro (Figura 1A) correspondem a um conjunto de bacias sedimentares

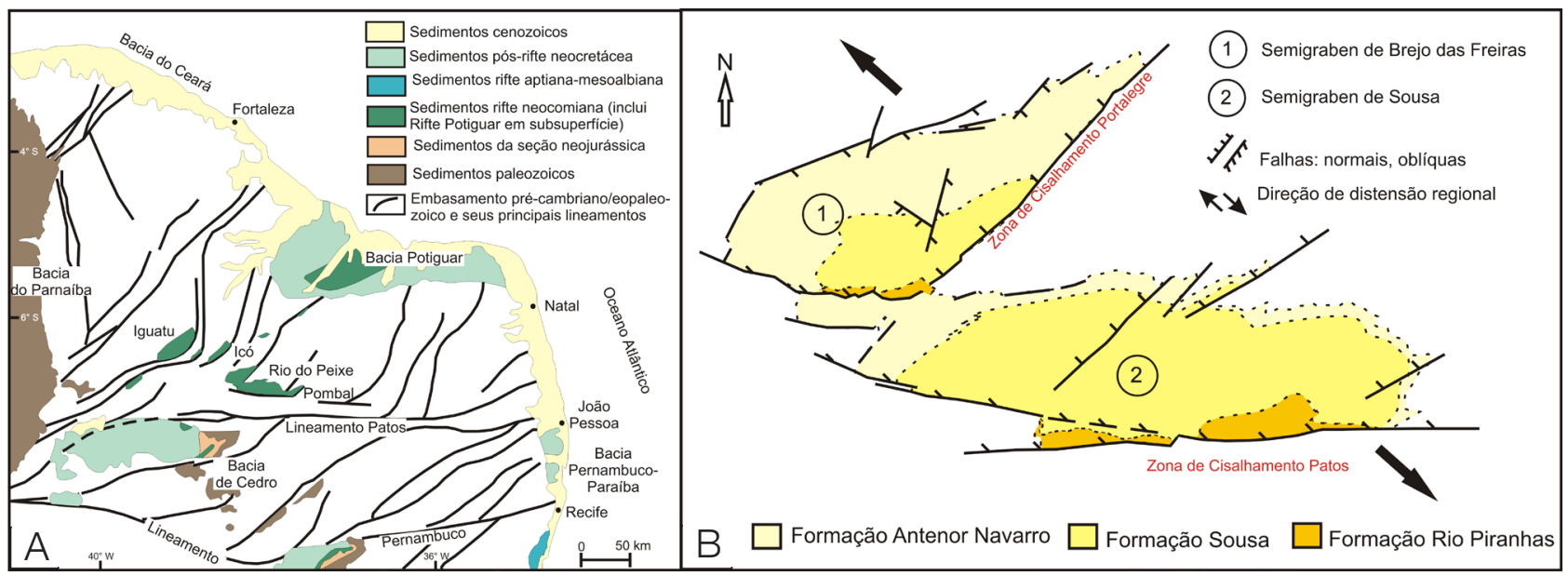

Figura 1. (A) Mapa geológico simplificado do NE do Brasil com os principais lineamentos estruturais e as bacias interiores (modificado de Ponte et al., 1991). A Bacia do Rio do Peixe localiza-se ao norte do Lineamento de Patos. (B) Mapa simplificado da Bacia do Rio do Peixe com as falhas principais. As zonas de cisalhamento, com trend NE e E-W (Z.C. Portalegre e Patos, respectivamente) controlaram a margem falhada dos semigrabens de Brejo das Freiras, com componente normal, e Sousa com componente oblíqua sinistral, associado ao evento distensivo NW-SE (modificado de Jardim de Sá et al., 2010). 
originadas a partir do preenchimento de depressões geradas na separação dos continentes africano e sul-americano, durante o fim do Jurássico e o Eocretáceo. Situadas ao norte de importante zona de cisalhamento pré-cambriana (o Lineamento Pernambuco), essas bacias pertencem ao trend Cariri-Potiguar, definindo um eixo de rifteamento Eocretáceo (Ponte et al., 1991; Françolin, 1992; Matos, 1992, 1999; Françolin et al., 1994; Ponte e Ponte Filho, 1996; Córdoba et al., 2008).

A Bacia do Rio do Peixe localiza-se imediatamente ao norte do Lineamento Patos, uma outra zona de cisalhamento com direção E-W e idade pré-cambriana, desenvolvida durante a Orogênese Brasiliana (600 - $550 \mathrm{Ma})$. Mais ao norte, a Zona de Cisalhamento Portalegre, de orientação NE, enraíza-se ao sul no Lineamento de Patos e compartimenta a Bacia do Rio do Peixe em duas sub-bacias: Brejo das Freiras, a oeste, e Sousa, a leste, essa última tendo se desenvolvido ao longo do Lineamento Patos (Figura 1B).

Françolin et al. (1994), Córdoba et al. (2008) e Nunes da Silva (2009) descreveram a geometria e cinemática das falhas que controlaram e deformaram a bacia. Segundo esses autores, a "reativação" das zonas de cisalhamento pré-cambrianas da bacia, durante o Eocretáceo, resultou em falhamentos com componente dominantemente normal para a falha de borda do Semigraben de Brejo das Freiras (ancorada em um dos ramos da Zona de Cisalhamento de Portalegre) e oblíqua normal-sinistral para o Semigraben de Sousa, controladas pela direção principal de distensão regional, NNW a NW.

Em ambas as sub-bacias é reconhecida uma margem flexural cujo contato da base da sequência sedimentar exibe geometria curva em mapa, truncando o fabric (fotolineações) do embasamento (Figura 1). Esse contato em não conformidade, ou envolvendo falhas com rejeito moderado (antitéticas à principal), é caracterizado na porção NW do Semigraben de Brejo das Freiras (além de Pombal e Icozinho, não consideradas neste estudo), e na porção norte do Semigraben de Sousa. As margens falhadas exibem a geometria retilínea em superfície, refletindo o controle das falhas principais, com direção E-W em Sousa (falha São Gonçalo) e em Brejo das Freiras (falha Brejo das Feiras), variando desde a direção NE para WNW, na junção com o Lineamento de Patos (Figura 1B). Rampas de revezamento são desenvolvidas ao longo dessas estruturas.

As unidades sedimentares da bacia, datadas do Eocretáceo, foram depositadas contemporaneamente ao evento distensional. Denominadas de Tectonossequência do Rio do Peixe, as formações Antenor Navarro e Sousa são basculadas contra a falha de borda, enquanto a Formação Rio Piranhas consiste em leques aluviais acompanhando a falha de borda (por questão de simplificação, essas formações não são individualizadas na Figura 1B. Estruturas sinclinais comumente ocorrem bordejando as falhas, formadas pela combinação do basculamento do semigraben (efeito regional) e flexuras desenvolvidas na propagação das falhas (dobras de arrasto, na concepção clássica).

\section{ABORDAGEM EXPERIMENTAL}

\section{Modelagem física na geologia}

A modelagem física tem sido utilizada na geologia desde o século XIX, com o objetivo de testar modelos tectônicos teóricos e analisar o desenvolvimento de estruturas geológicas naturais. Como premissa, a modelagem baseia-se na teoria da similaridade, adaptada à geologia por Hubbert (1937), que permite a comparação entre as estruturas geológicas naturais e os modelos físicos.

Os trabalhos em modelagem física envolvem diferentes tipos de ambientes tectônicos, possibilitando uma melhor compreensão de como as estruturas geológicas nucleiam e se desenvolvem. Segundo McClay (1990), a modelagem física tem sido fundamental no estudo do desenvolvimento e da evolução de bacias sedimentares e de sistemas de falhas, por ser possível observar os mecanismos responsáveis pela geometria e cinemática dessas estruturas. A modelagem de ambientes distensionais permite uma abordagem detalhada de temas como os processos que controlam a evolução do sistema de falhas e/ou mudança de polaridade de semigrabens, o padrão de falhas internas e de borda, a segmentação de falhas e zonas de transferência, a evolução e arquitetura de riftes (McClay e Bonora, 2001; Schlische et al., 2002; Morley et al., 1990; Nelson et al., 1992).

Para uma melhor correlação entre o modelo físico e o natural, é necessário que o comportamento dos materiais usados no ensaio experimental seja análogo ao das rochas na crosta (Tron e Brun, 1991; McClay e White, 1995; Bonini et al., 1997). Além dos materiais mais convencionais (areia quartzosa, argila, silicone), utilizados na simulação de rochas da crosta superior (Dooley e McClay, 1997; Clifton et al., 2000), vários outros materiais têm sido testados e empregados em experimentos diversos, tais como gesso, mel, gelatina, mica e microesferas de vidro, entre outros (Lohrmann et al., 2003; Henza et al., 2011; Teixell e Koyi, 2003; Panien et al., 2006). No caso dos modelos escalados é necessário que haja, entre o modelo e o protótipo experimental, similaridade geométrica, cinemática e dinâmica nos modelos testados.

\section{Materiais e equipamentos utilizados neste estudo}

Nos experimentos aqui descritos utilizou-se areia quartzosa (oriunda das dunas da cidade de Natal) e pó de gesso. Para simular as rochas do embasamento, empregou-se uma mistura homogênea de areia e gesso na proporção (em volume) de $85 \%$ (areia) e $15 \%$ (gesso). Nesse composto, parte do gesso 
é adsorvido à superfície dos grãos de quartzo enquanto outra parte preenche os interstícios inter-grãos (Figura 2), o que dota a mistura de um comportamento mais frágil (do que a areia pura) quando submetido à distensão.

Para representar os sedimentos sintectônicos, utilizou-se areia quartzosa tingida artificialmente, para possibilitar a visualização dos estratos por meio do contraste de cor. Embora alguns autores tenham sugerido que a tinta utilizada possa influenciar no comportamento reológico da areia (ver Gomes e Caldeira, 2011, para maiores detalhes), essa eventual modificação foi julgada irrelevante neste trabalho, em termos de alteração dos resultados obtidos.

O aparato é constituído por quatro paredes de vidro com dimensões aproximadas de $50 \times 34 \times 24 \mathrm{~cm}$ (comprimento, largura e altura, respectivamente), sendo 3 delas fixas e uma móvel. Esta última é fixa em um braço mecânico de um motor elétrico que a move em velocidade constante (Figura 3).

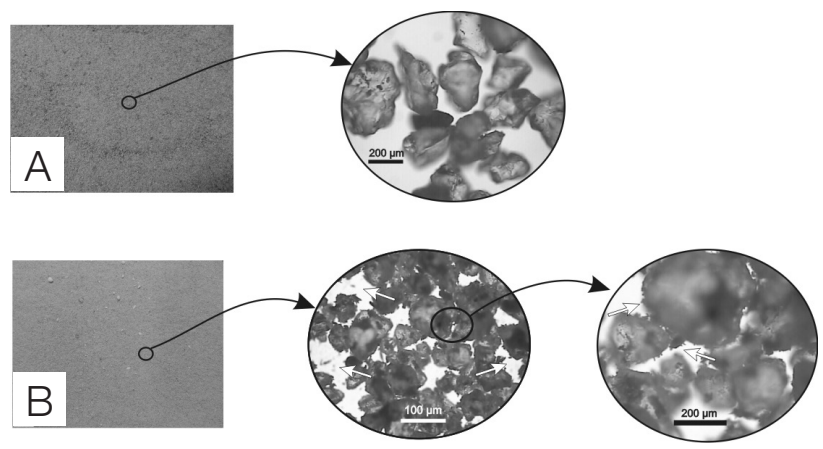

Figura 2. (A) Fotografia de areia fina a média, tingida de verde e cuja morfologia dos grãos é mostrada na fotomicrografia no detalhe. (B) Fotografia macroscópica da mistura de areia e gesso (85 e 15\%, respectivamente). Nos detalhes, visão microscópica da mistura areia/gesso. As setas brancas destacam, à esquerda, o gesso no espaço inter-grãos e, no detalhe à direita, gesso adsorvido pelos grãos de quartzo.

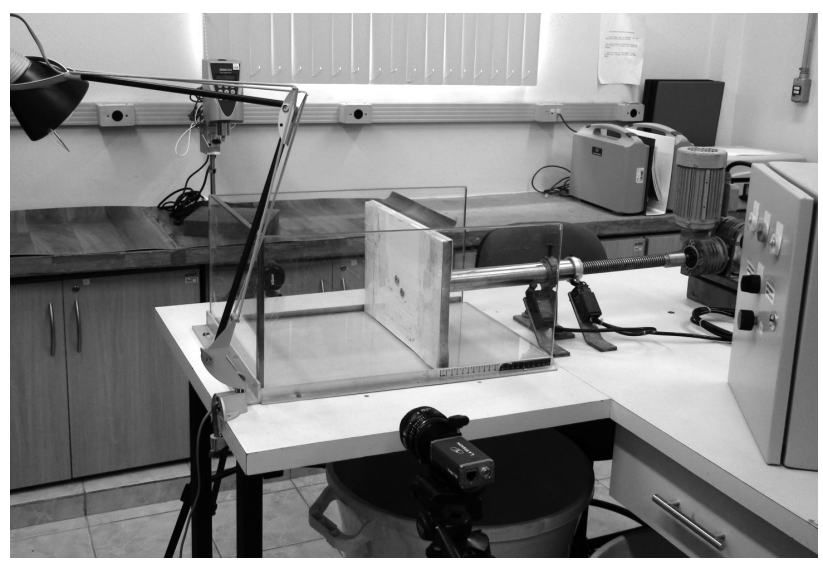

Figura 3. Fotografia do aparato deformacional mostrando a caixa de vidro (caixa de areia) e o motor responsável pela movimentação da parede móvel.

\section{Montagem dos modelos}

O objetivo dos experimentos foi simular a influência/importância de descontinuidades do embasamento (zonas de fraqueza) na nucleação e no desenvolvimento das bacias, quando da sua reativação em regime frágil. Nas bacias interiores do Nordeste do Brasil, essas descontinuidades são as zonas miloníticas brasilianas. Para nuclear as falhas, as descontinuidades do embasamento foram simuladas colocando, na base do aparato, uma anisotropia (descontinuador de velocidade - Dv) representada por papel vegetal com uma extremidade contendo a geometria que se desejava simular e a outra presa à parede móvel e movimentandose à mesma velocidade desta (Figura 4). Os experimentos foram repetidos pelo menos três vezes, para testar a reprodutividade dos resultados. Nos dois primeiros tipos de experimentos desenvolvidos, o Dv representa uma descontinuidade nucleadora das falhas que vão controlar os semigrabens de abertura ortogonal e oblíqua (Figuras 4A e 4B). No terceiro tipo de experimento, o Dv representava as descontinuidades nucleadoras das falhas nos semigrabens ortogonal e oblíquo, desenvolvidos simultaneamente durante o evento de distensão (Figura 4C).

$\mathrm{O}$ material granular simulando o embasamento foi peneirado na caixa de areia de altura média de $10 \mathrm{~cm}$, até as camadas alcançarem de 2,5 a 3,0 $\mathrm{cm}$ de espessura. $\mathrm{O}$ experimento foi realizado com a movimentação da parede móvel a uma velocidade constante de $0,42 \mathrm{~mm} \cdot \mathrm{s}^{-1}$. A distensão máxima nos experimentos variou de 14 a $26 \%$. Essa variação deve-se ao fator dificuldade/facilidade de as bacias serem nucleadas e se desenvolverem, fator que depende de sua orientação em relação à direção de distensão.

A sedimentação sintectônica foi simulada pela adição (também via peneiramento), na área da bacia, de areia quartzosa colorida artificialmente (para facilitar a visualização das estruturas).

A fim de facilitar a correlação da orientação das estruturas geradas nos experimentos com aquelas da Bacia do Rio do Peixe, assumiu-se uma orientação arbitrária de distensão, ou seja, NW-SE, simulando a distensão eocretácea atuante na região Nordeste do Brasil.

\section{Aquisição e tratamento dos dados}

Durante o experimento foram obtidas fotografias do topo da superfície dos modelos em intervalos distintos, sequenciais. Essas fotos foram usadas para caracterizar a nucleação e o desenvolvimento do sistema de falhas, o comprimento individual e a orientação das falhas, bem como a evolução da geometria da bacia. No fim do experimento, o modelo foi endurecido e cortado em seções transversais, de modo que obtivesse perfis em diversos setores da bacia (Figura 5A). Essas seções foram fotografadas (Figura 5B) 


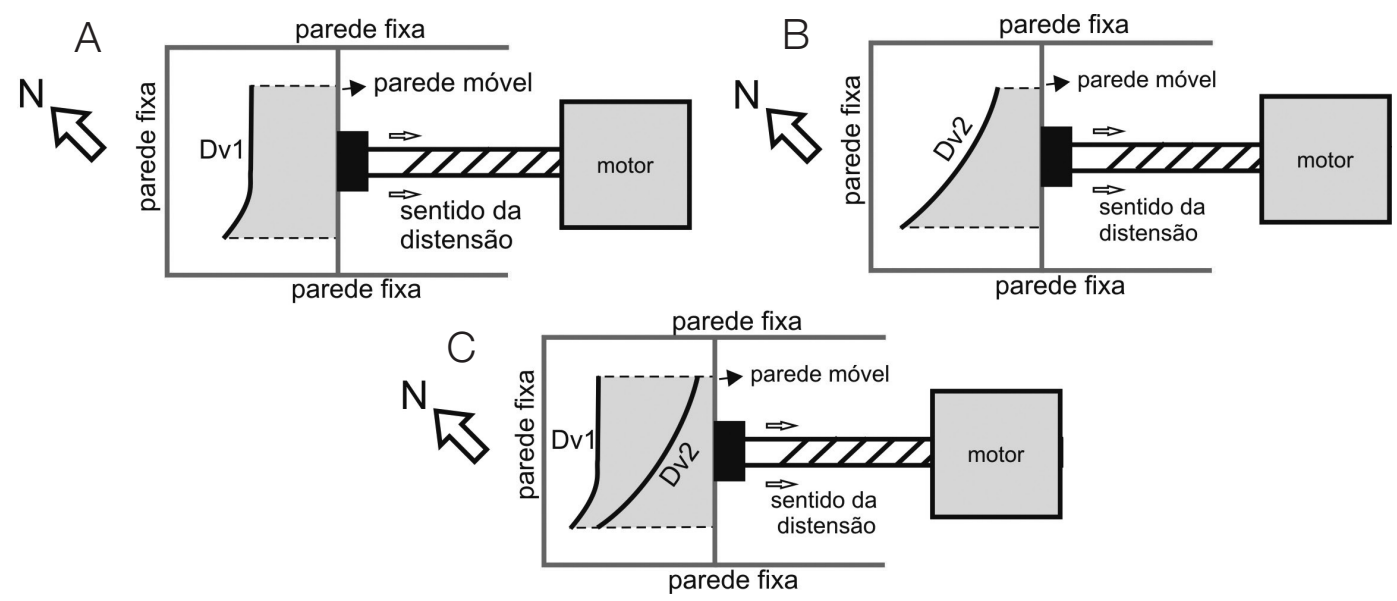

Figura 4. Representação da parte basal (planta) do aparato, onde a folha de papel vegetal (cinza) com a geometria do descontinuador de velocidade (Dv) representa a anisotropia pré-existente. Em (A) arquitetura basal para distensão ortogonal (simulando o Semigraben de Brejo das Freiras) e em (B) oblíqua (simulando o Semigraben de Sousa), ambos desenvolvidos de forma independente; comparar com o mapa da Bacia do Rio do Peixe, na Figura 1. (C) Distensão gerando os semigrabens ortogonal e oblíquo, simultaneamente. As setas pretas indicam a direção do movimento distensional.

e utilizadas na análise do comportamento das falhas (de borda e interiores às bacias) em profundidade, em termos de sua geometria, espaçamento, rejeito e outros atributos. Os mergulhos aparentes, quando utilizados para comparação entre modelos, foram corrigidos matematicamente para possibilitar essa comparação.

\section{EVOLUÇÃO INDEPENDENTE DOS SEMIGRABENS}

Nesta seção serão discutidos dois tipos de experimentos, nos quais as bacias ortogonal e oblíqua à direção de distensão foram geradas de forma independente, sem interferência mútua no processo de desenvolvimento.

\section{Formação de semigrabens por meio de distensão ortogonal à descontinuidade preexistente}

Nesta série de experimentos distensionais, a bacia se desenvolve com seu eixo maior perpendicular à direção de distensão; no análogo natural, esse é o caso do Semigraben de Brejo das Freiras. Essa relação angular se modifica nas terminações, onde podem ser definidos setores do tipo rampa oblíqua, que não serão abordados neste item (mas considerados adiante, neste trabalho). De forma geral, a bacia mostra o desenvolvimento de uma margem delimitada por uma falha bem marcada, com rejeito normal, enquanto que na margem flexural foram formadas algumas falhas segmentadas, de menor dimensão. Durante o seu desenvolvimento, a bacia se alargou e parte das falhas mais precoces, próximas à margem flexural, diminuíram a sua atividade (podendo até mesmo se tornar inativas) e, quando recobertas pelos
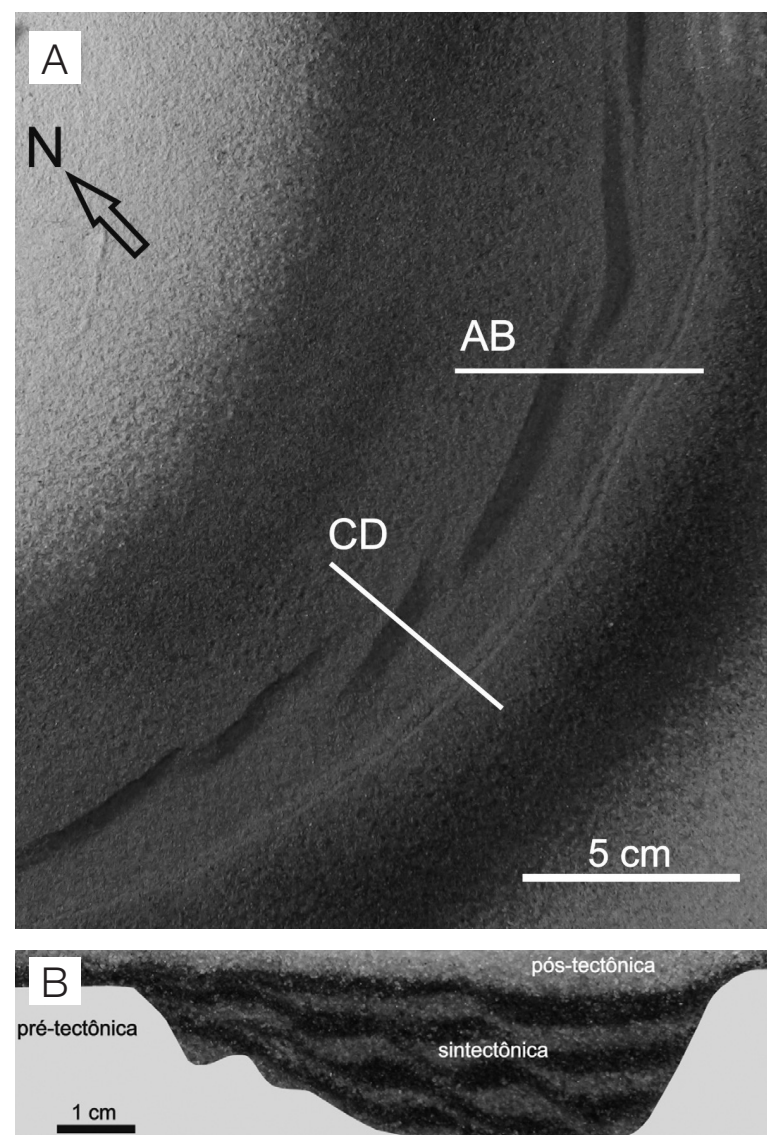

Figura 5. (A) Exemplo de fotografia da superfície do modelo com a marcação onde ele foi seccionado para a geração dos perfis. Estes perfis podem ser paralelos à direção de distensão (AB) ou perpendiculares à borda da bacia (CD). (B) Exemplo de fotografia de um corte, ilustrando o comportamento das falhas em subsuperfíce. (A e B) são fotografias de modelos distintos. 
sedimentos sintectônicos, podem ter ficado restritas à subsuperfície. No interior da bacia, as camadas foram basculadas e foi desenvolvido um sistema de falhas antitéticas em relação à falha de borda, subparalelas entre si (leque imbricado). Flexuras geradas na propagação das falhas de borda e antitética resultam no desenvolvimento de uma estrutura sinformal que marca o principal depocentro da bacia.

\section{Caracterização das falhas de borda}

Nos primeiros estágios de deformação a margem falhada exibe, em mapa, uma geometria segmentada, cujos segmentos coalescem nos estágios subsequentes, dando origem à principal falha da bacia (Figura 6); no caso de Brejo das Freiras, localizada na borda sudeste, com orientação NE, mergulho para NW e cinemática normal.

Em perfil, a falha principal da bacia gerada no modelo, na borda sudeste, apresenta geometria tendendo à lístrica, com o mergulho passando de cerca de $75^{\circ}$ próximo à superfície para cerca de $50^{\circ} \mathrm{em}$ profundidade. Essa variação de mergulho pode sofrer alterações ao longo da falha, principalmente se considerarmos a extremidade oblíqua da bacia, como ilustrado na Figura 7.

Diferentemente da margem sudeste, a margem noroeste da bacia, dita flexural, é marcada pelo desenvolvimento
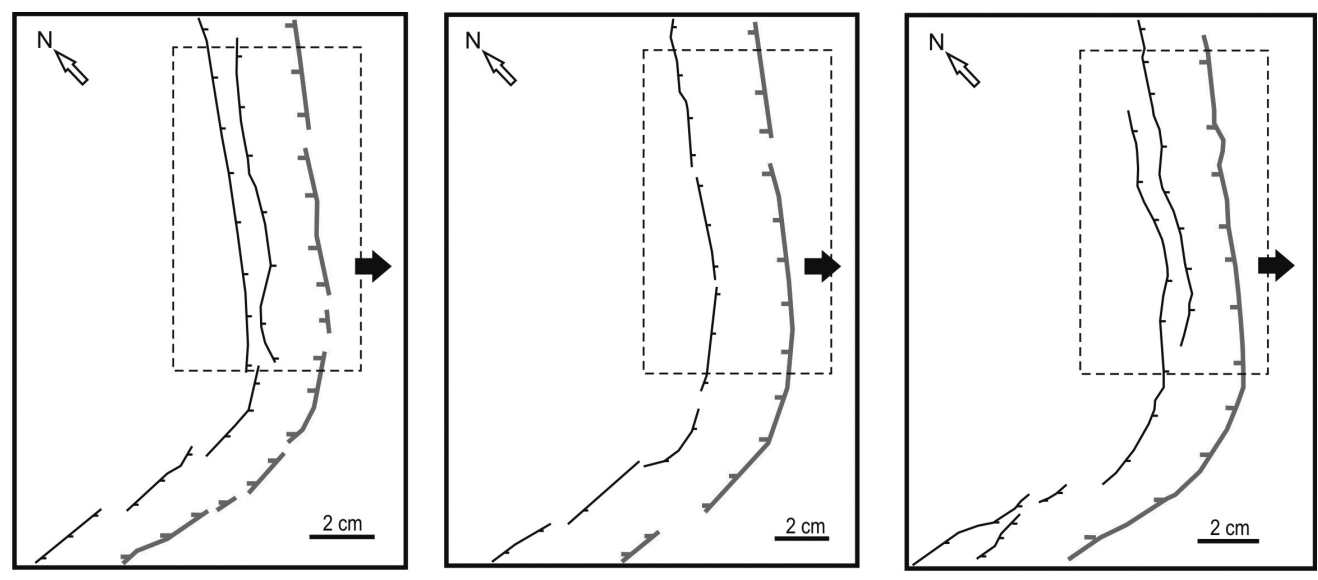

aumento da deformação

Figura 6. Representação em mapa, a partir de fotografias, da evolução $(\varepsilon=7,9,5$ e $14 \%$, respectivamente) da principal falha da bacia modelada, que define a denominada margem falhada. O retângulo tracejado delimita a porção ortogonal da bacia, que ao longo dessa estrutura transiciona (na porção sul) a uma rampa oblíqua (falha de transferência).

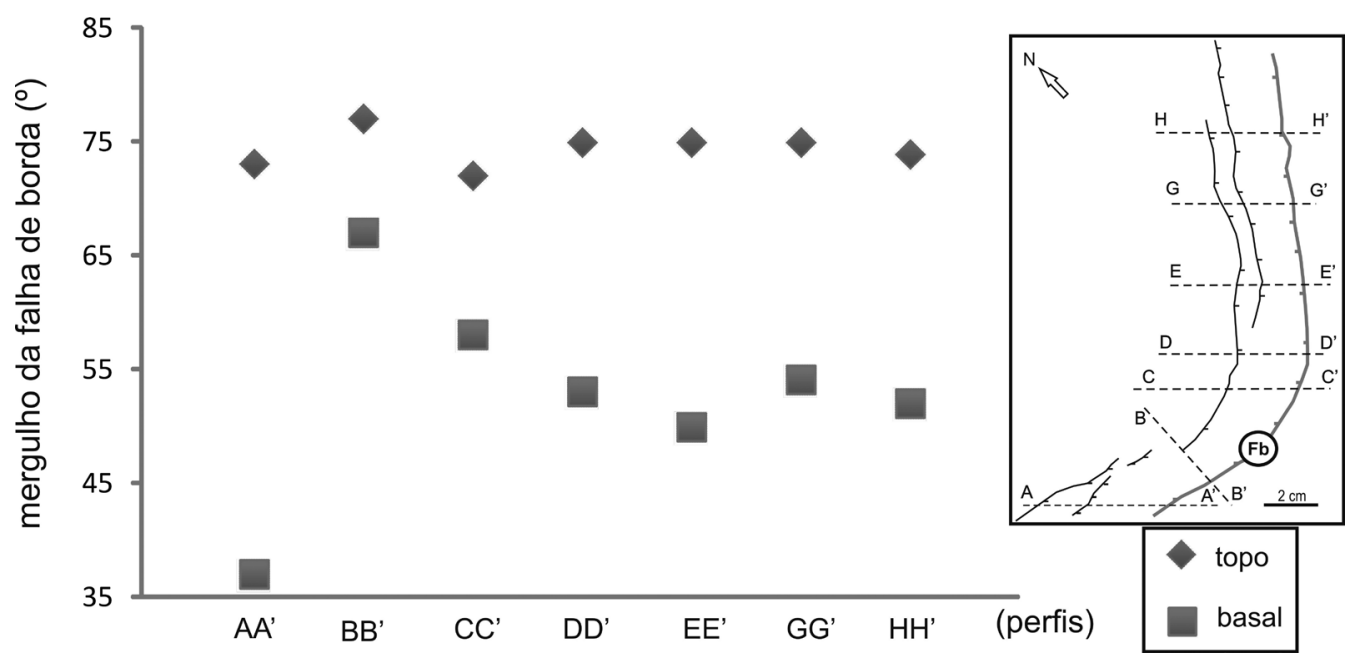

Figura 7. Representação gráfica da intensidade dos mergulhos da falha de borda (Fb), obtida nos perfis ao longo da bacia. O inset mostra a localização dos perfis na bacia. Os mergulhos nas partes superiores das falhas são mais constantes que nas porções basais. Os mergulhos das falhas obtidos nos modelos ao longo dos perfis AA' e BB' são aparentes por situarem-se na porção oblíqua da bacia, então foram corrigidos matematicamente. AA', BB', CC", DD”, EE”, GG' e HH" representam os perfis mostrados no inset. 
de rampas de revezamento, originadas devido à presença de segmentos de falhas escalonadas (Figura 8). Esses segmentos de falhas têm trend NE e mergulho forte para SE. Um fato a observar é que o mergulho de uma das rampas de revezamento foi invertido ao longo da deformação, sugerindo variação do rejeito ao longo dos planos de falhas, com os incrementos sucessivos da deformação.
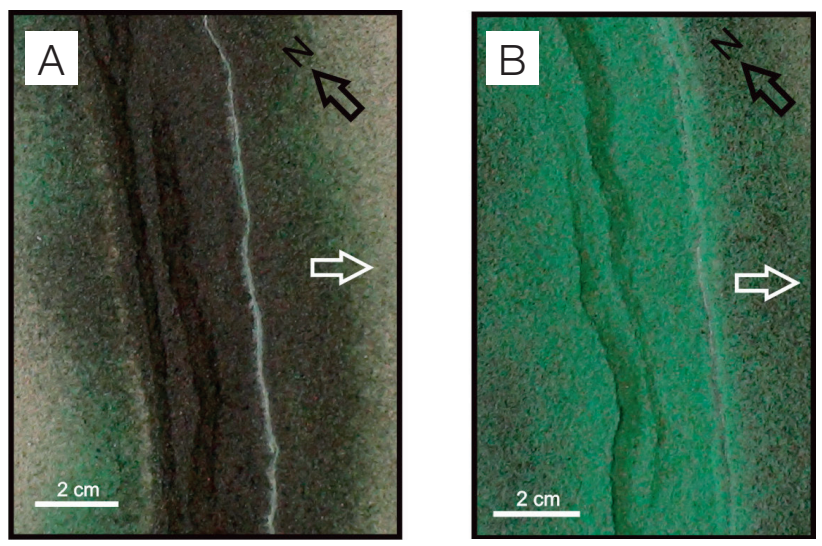

Figura 8. Fotografia do topo do modelo (superfície), em dois estágios distintos da evolução da bacia, mostrando a presença de rampa de revezamento na margem flexural. Notar a inversão do mergulho da rampa, do estágio mais precoce (A) para um estágio mais avançado (B). A seta branca indica a direção da distensão.

\section{Análise da geometria das falhas internas à bacia}

A estruturação interna da bacia é marcada por um conjunto de falhas antitéticas à falha de borda e um número reduzido de falhas sintéticas. Algumas dessas falhas antitéticas não chegam a se propagar nas camadas sintectônicas mais superiores e, assim, não são observadas na superfície. As falhas sintéticas, por sua vez, estão restritas à seção inferior do preenchimento sedimentar da bacia e situam-se bem próximas à falha de borda (Figura 9). Embora o número de falhas permaneça praticamente constante ao longo do experimento, observase, de sudoeste para nordeste (perfís DD', EE' e GG' na Figura 9), uma diminuição no espaçamento das falhas. No sentido inverso (de GG' para DD') há um aumento no rejeito da falha antitética que define o depocentro da bacia (falha f na Figura 9B).

No que diz respeito à intensidade do ângulo de mergulho das falhas internas à bacia, nota-se uma variação em função da sua localização, tendo como referência a falha de borda (Figura 10). De modo geral, as falhas que apresentam mergulho mais forte são aquelas mais próximas às bordas sudeste e noroeste, com uma diminuição nas porções mais centrais. Excetuando as falhas do perfil GG', todos os demais perfis mostram que as falhas internas mais distantes da margem falhada exibem mergulhos ligeiramente superiores àquelas mais próximas à falha principal (Figura 10).
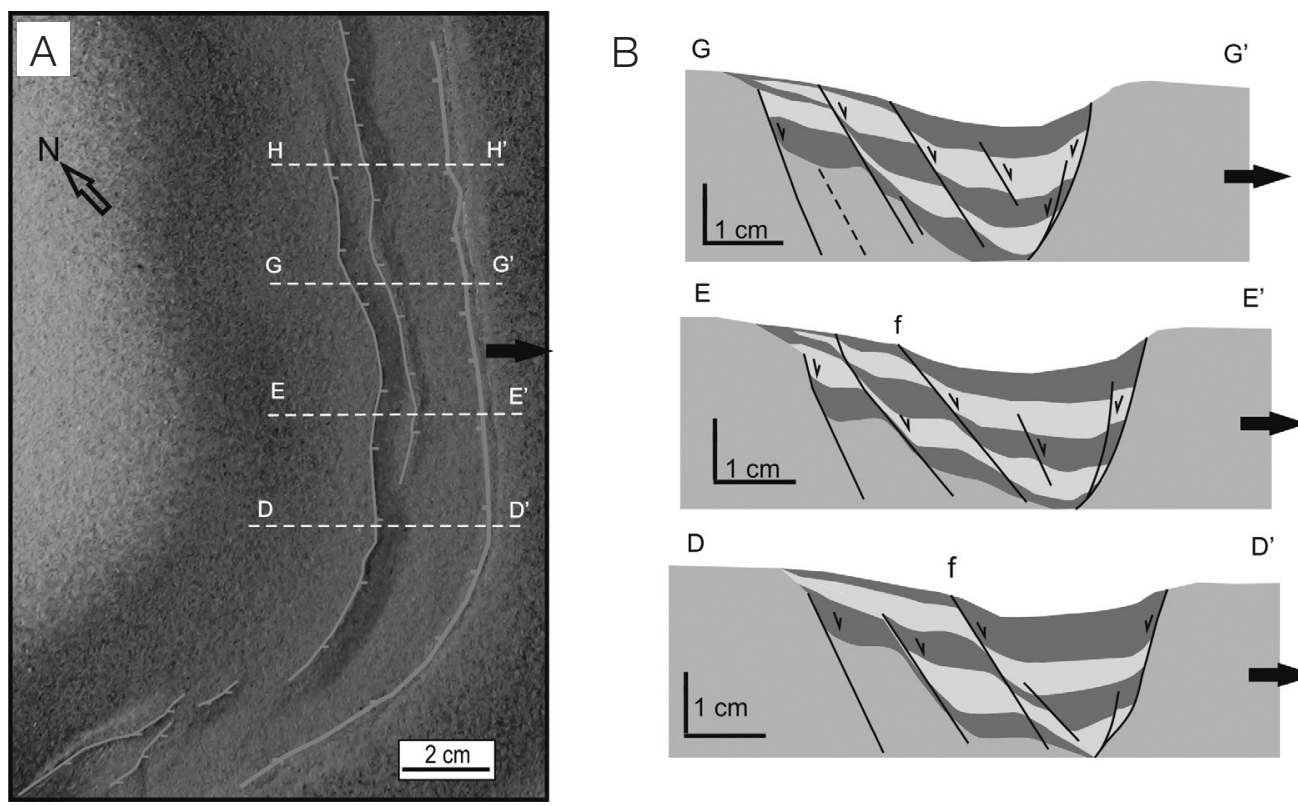

Legenda:
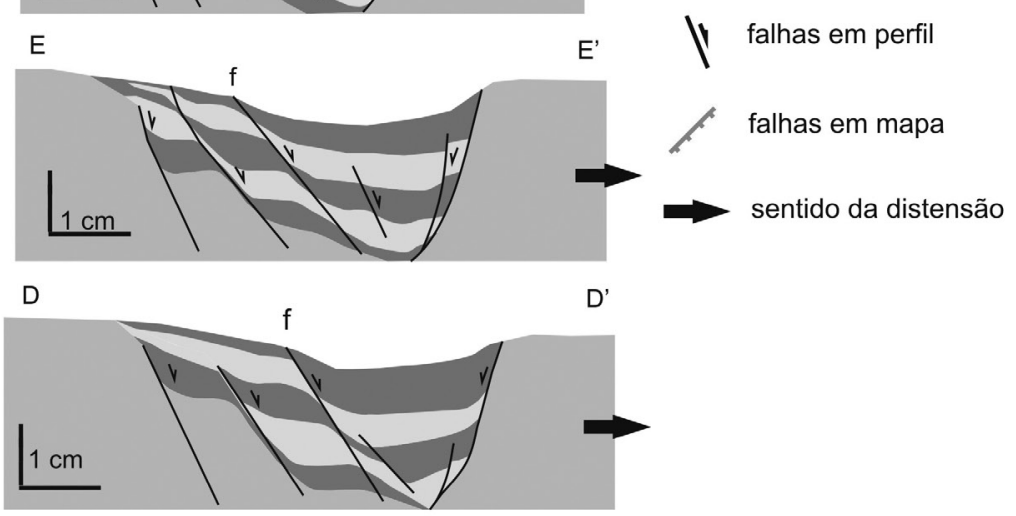

Figura 9. (A) Representação em mapa da bacia ortogonal $(\varepsilon=14 \%)$, com a localização dos perfis mostrados em (B). Exemplo da estruturação interna da bacia ortogonal é mostrado em (B), onde se nota pequena alteração no espaçamento das falhas e no rejeito de algumas delas (falha f, por exemplo). Notar que algumas falhas não atingem a superfície. 


\section{Formação de semigrabens por meio de distensão oblíqua à descontinuidade preexistente}

Este ensaio experimental exemplifica o desenvolvimento de uma bacia cuja orientação é oblíqua à direção de distensão; no análogo natural, esse é o caso do Semigraben de Sousa. As condições de contorno são idênticas àquelas dos experimentos descritos anteriormente, diferindo apenas na orientação da descontinuidade prévia nucleadora da bacia (Dv, Figura 4B).

O monitoramento da largura da bacia $(\omega)$ foi feito medindo, em um mesmo local na superfície, a distância entre as duas margens (delimitadas pelas falhas mais externas aflorantes) nos diversos incrementos deformacionais.
Nos estágios iniciais de distensão a abertura da bacia é feita de forma relativamente homogênea (até cerca de 9,6\% de distensão, Figura 11A) e, depois de estabilizada em uma mesma largura durante alguns incrementos adicionais, passa a exibir um comportamento irregular (Figura $11 \mathrm{~A})$. Esse comportamento é interpretado como devido à migração da deformação da margem flexural em direção ao centro da bacia, com geração de falhas em overstep, com o aumento da distensão e sendo parcialmente recoberta pela sedimentação sintectônica, fazendo variar o valor de $\omega$ Figura 11B).

Ao longo da margem flexural da bacia foi desenvolvido um sistema de falhas antitéticas à falha principal que se

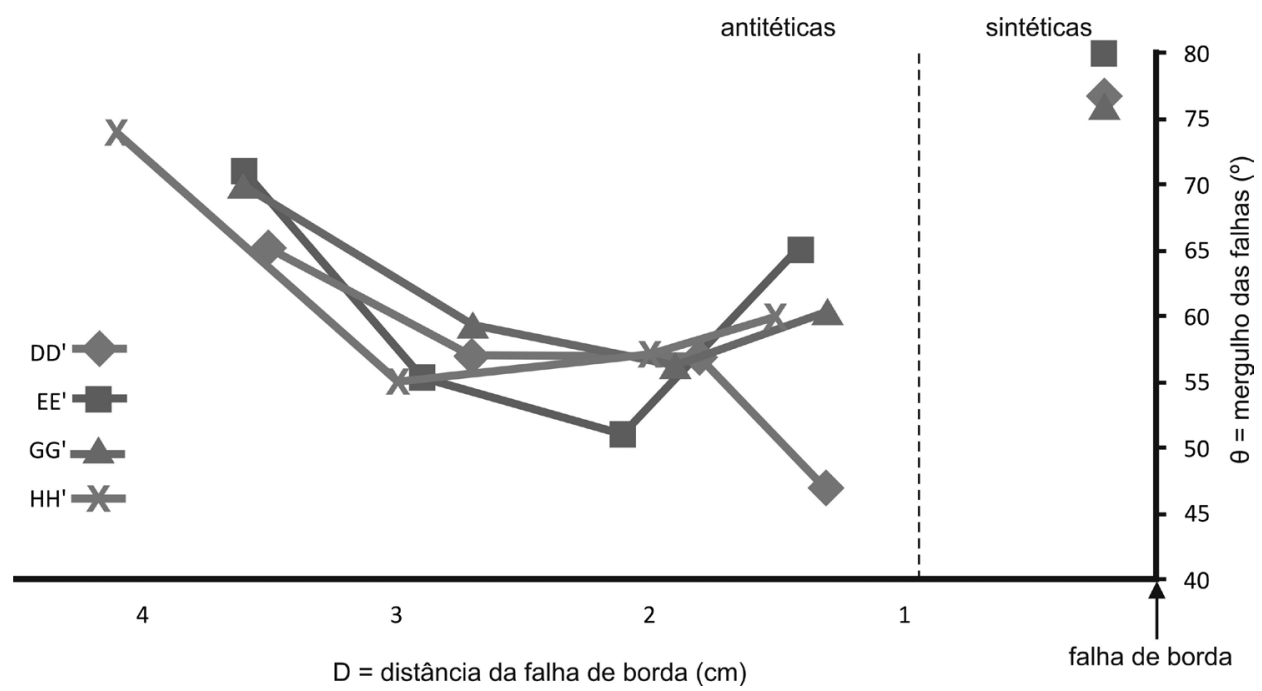

Figura 10. Relação entre o ângulo de mergulho $\left(\theta^{\circ}\right)$ das falhas internas (antitéticas e sintéticas) da bacia e a distância (D) à falha de borda da bacia. Notar mergulhos menores na parte central da bacia. A localização dos perfis é ilustrada na Figura $9 \mathrm{~A}$.

A

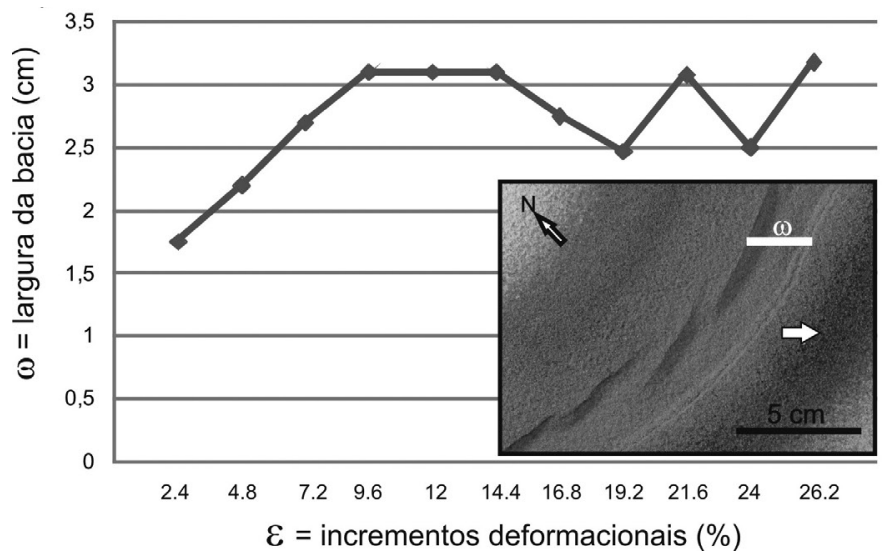

B

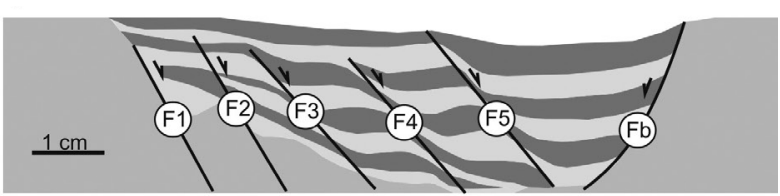

embasamento

camadas sedimentares sintectônicas

It falhas em perfil

Figura 11. (A) Gráfico mostrando o desenvolvimento da abertura da bacia ( $\omega$ ) ao longo dos diversos incrementos deformacionais. A foto mostra um exemplo da obtenção de $\omega$. (B) Perfil ilustrando o desenvolvimento sequencial das falhas no interior da bacia, com propagação em direção ao centro da bacia (F1 a F5). A falha de borda é representada por Fb. 
apresentam escalonadas (Figura 12A) e com provável rejeito normal-oblíquo. O escalonamento dessas falhas gera degraus em subsuperfície (Figura 12B). A flexura das camadas sintectônicas, na falha principal e na falha antitética mais próxima, é responsável pela presença de uma estrutura sinclinal nessa região.

\section{Caracterização das falhas de borda}

A falha da borda sul da bacia é representada por um grande segmento central desenvolvido nos estágios iniciais e alguns segmentos menores nas extremidades leste e oeste, os quais coalescem formando um grande semiarco com suave concavidade para o norte (Figura 13).
A falha de borda exibe mergulho mais acentuado próximo à superfície e menor em profundidade, com tendência a formar uma geometria lístrica. Essa geometria é menos pronunciada nos perfis EE' e GG' (perpendiculares a bacia) (Figura 14). A intensidade do mergulho dos segmentos superiores e basais da falha varia de acordo com sua posição na bacia (Figura 14).

A margem norte da bacia (flexural) é marcada pela presença de pequenos segmentos de falha escalonados e não paralelos, delineando uma geometria curva com concavidade para norte e cujo traço geral é paralelo à margem falhada (Figura 15). O arranjo geométrico desses segmentos provoca o desenvolvimento de diversas rampas de revezamento com declividade para sudoeste.

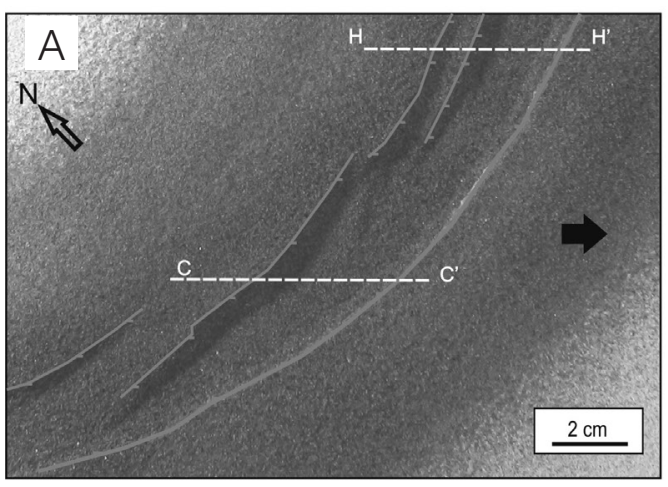

B

$\mathrm{H}$

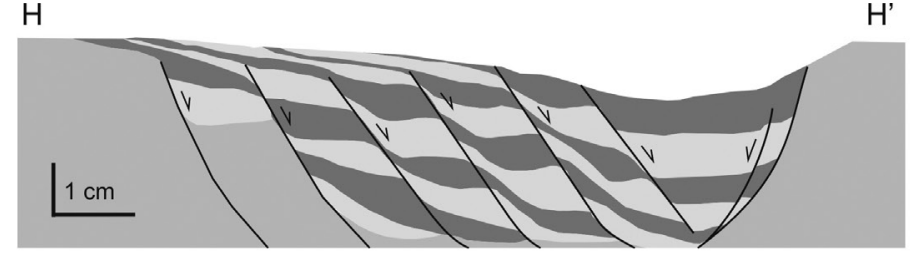

C

$C^{\prime}$

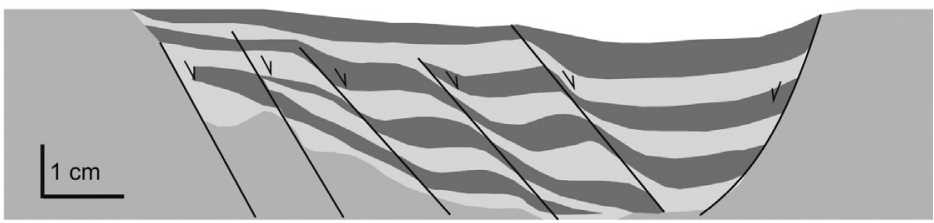

embasamento

falhas em perfil

sentido da distensão

falhas em mapa

camadas sedimentares sintectônicas

Figura 12. Mapa e perfis mostrando a distribuição das falhas oblíquas/normais na superfície e subsuperfície da bacia oblíqua (em relação à direção de distensão). Notar que a maioria das falhas antitéticas não aflora no estágio deformacional ilustrado em (A), sendo encobertas pela sedimentação sintectônica, como pode ser observado nos perfis de (B).
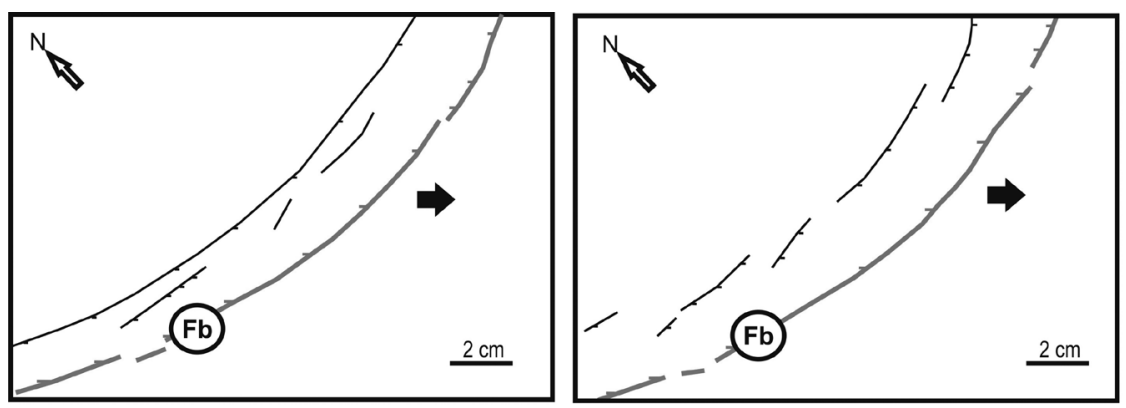

aumento da deformação

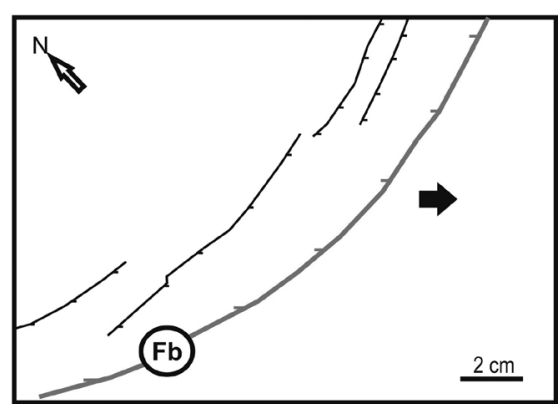

Figura 13. Desenvolvimento da falha de borda $(\mathrm{Fb})$ da bacia oblíqua, em três estágios da deformação $(\mathcal{E}=5,13$ e $18 \%$, respectivamente), ilustrando a coalescência de seus segmentos. 


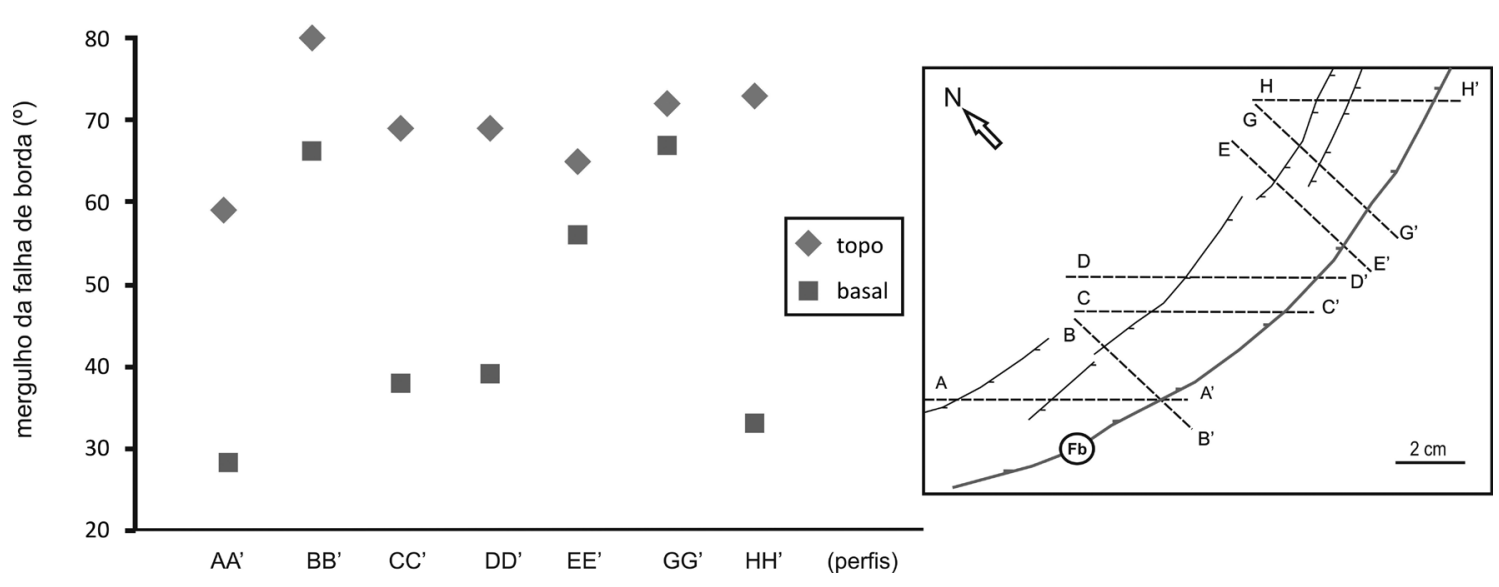

Figura 14. Variação da intensidade do mergulho da falha de borda $(\mathrm{Fb})$ entre as porções mais superficiais e mais profundas da bacia ao longo de perfis paralelos à direção de distensão (AA', CC', DD', HH') e aproximadamente perpendicular à bacia (BB', EE' e GG'). Os mergulhos aparentes, obtidos no modelo, foram corrigidos matematicamente.
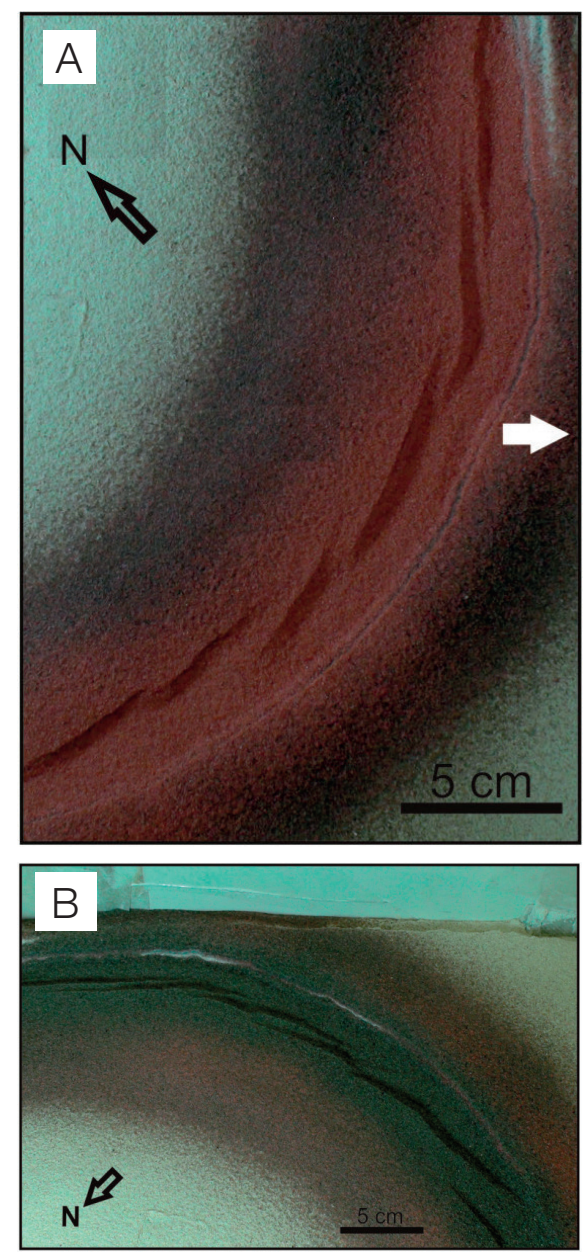

Figura 15. Vista em mapa (A) e em perspectiva (B) de segmentos de falhas escalonados na margem flexural da bacia, oblíqua à direção de distensão (seta branca). Entre os segmentos há a formação de rampas de revezamento com mergulho para sudoeste.

\section{Análise da geometria das falhas internas à bacia}

O estudo das falhas no interior da bacia foi feito em dois tipos de perfis, paralelos à direção de distensão e aproximadamente perpendiculares à bacia. Em ambos os casos, observa-se o desenvolvimento de um sistema de falhas normais antitéticas bem marcado, enquanto as falhas sintéticas da falha principal são bastante subordinadas (Figura 16). O depocentro da bacia localiza-se sempre entre a falha de borda e a primeira grande falha antitética.

Nos perfis paralelos à direção de distensão, embora o número de falhas não seja muito diferente, o espaçamento entre elas é distinto. Na parte mais central da bacia (perfil DD'), a distância entre as falhas bem como o rejeito da maioria delas são maiores que aqueles nas extremidades da bacia (perfil AA') (Figura 16). Os mergulhos dessas falhas, via de regra, são maiores nas porções mais distantes da falha de borda. O comportamento dos mergulhos nos perfis centrais da bacia (CC' e DD') é bastante similar (Figura 17A). Nos perfis perpendiculares à bacia observa-se, no geral, um número maior de falhas que no grupo anterior. Isso se deve ao caráter segmentado das falhas (são mais abundantes em algumas partes da bacia) e a localização dos perfis (Figura 16). O comportamento do mergulho das falhas é similar ao do grupo anterior, com uma diminuição do ângulo das falhas da porção central da bacia em relação àquelas das porções mais afastadas da falha de borda (Figura 17B). O cenário descrito acima é interpretado como devido a uma maior rotação dos planos de falhas da porção central da bacia durante a deformação, resultando em mergulhos relativamente mais baixos. Outro fator que pode contribuir para essa diferença é o comportamento reológico das camadas seccionadas pelas falhas. 
Perfis paralelos à direção de distensão

D

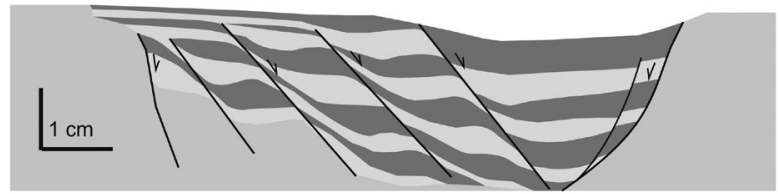

Perfis perpendiculares à bacia

G

G'

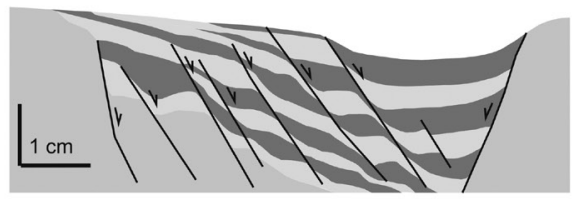

E

$E^{\prime}$

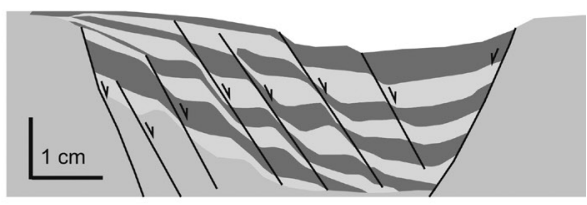

A

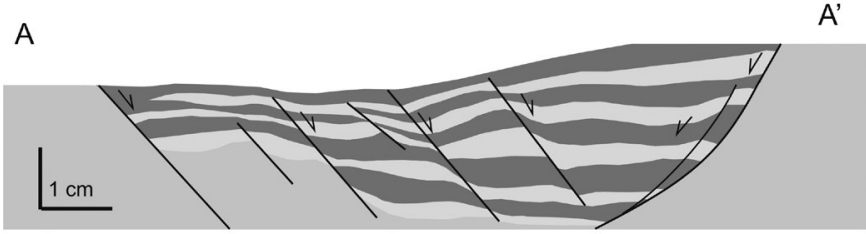

$A^{\prime}$

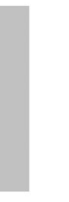

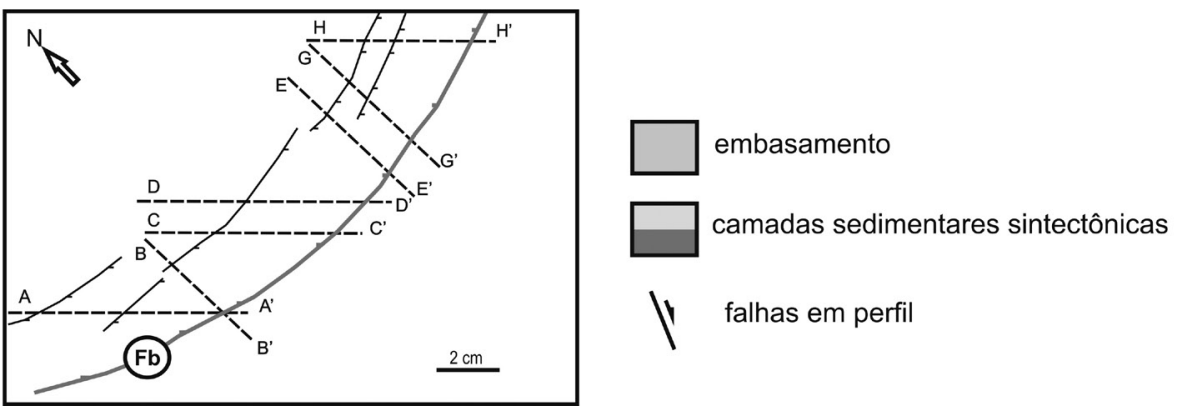

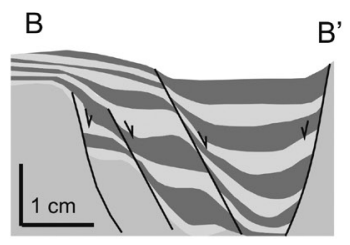

Figura 16. Ilustração dos dois conjuntos de perfis obtidos no experimento com bacia oblíqua: paralelos à direção de distensão (AA', DD') e perpendiculares à falha de borda (BB', EE' e GG') da bacia. A localização dos perfis é mostrada no inset (lado inferior esquerdo da figura), onde a falha de borda é designada por Fb.
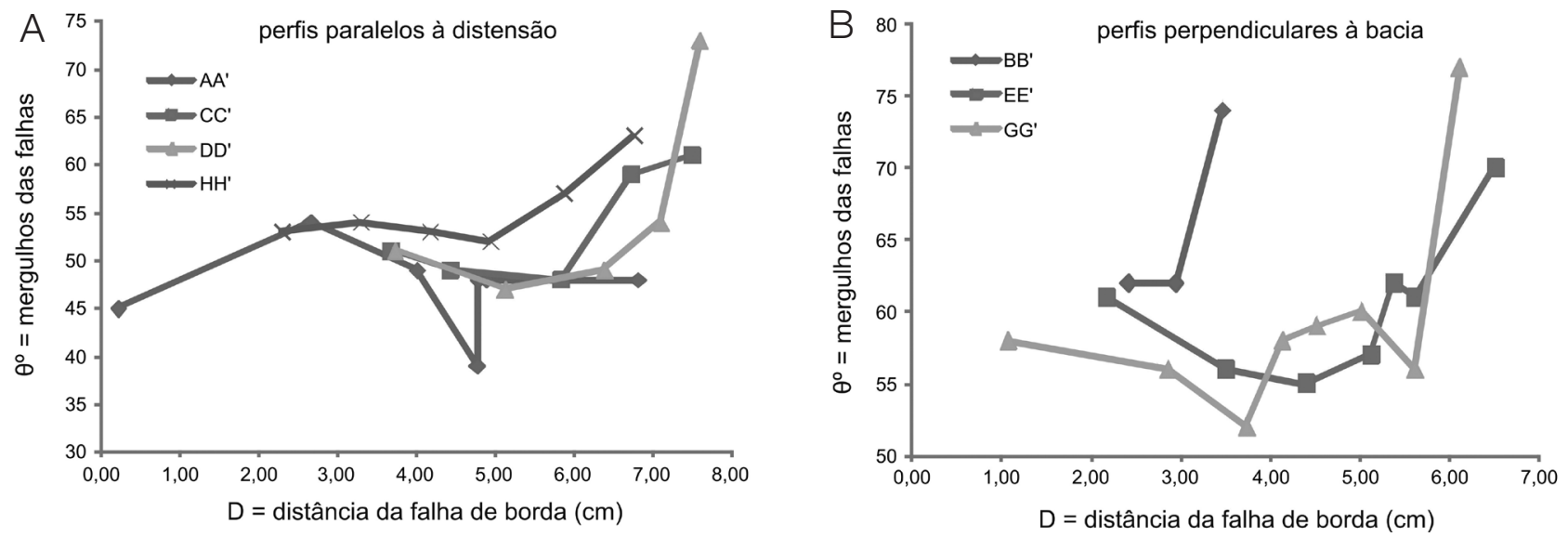

Figura 17. Representação gráfica da relação entre a distância das falhas antitéticas e a falha de borda e seu mergulho. Em (A) estão representados os perfis paralelos à direção de distensão e, em (B), os perfis perpendiculares à bacia. Em ambos os gráficos nota-se que as falhas da porção central da bacia exibem mergulhos ligeiramente inferiores àqueles das falhas mais afastadas da falha de borda. 
As falhas mais exteriores afetam grande parte do embasamento, enquanto as falhas mais centrais afetam principalmente as camadas sintectônicas (Figura 12B).

\section{FORMAÇÃO SINCRÔNICA DE SEMIGRABENS ORTOGONAIS E OBLÍQUOS À DIREÇÃO DE DISTENSÃO}

Nesses experimentos simulou-se a geração simultânea de duas bacias, induzidas por zonas de fraqueza do embasamento, orientadas ortogonal ou obliquamente à direção de distensão. Assim, é possível comparar as estruturas geradas nas bacias com aquelas geradas individualmente, como descritas nos modelos precedentes, e avaliar a possível influência que a simultaneidade possa ter no arcabouço estrutural das bacias. Os procedimentos experimentais foram iguais aos dos experimentos precedentes, com exceção da geometria das zonas de fraquezas simuladas pelos DVs (Figura 4C).

A bacia ortogonal iniciou o processo de abertura antes da oblíqua. A velocidade de abertura das bacias oscilou no tempo, o que implica a variação da intensidade de abertura. Ora a bacia ortogonal abria mais rapidamente que a oblíqua, ora o inverso ocorria. Em ambas as bacias foi implantada uma margem com falhas bem desenvolvidas e, nas suas porções internas, as falhas antitéticas dominaram sobre as sintéticas.

\section{Caracterização das falhas de borda}

O desenvolvimento das margens falhadas é bem visível em mapa durante todos os estágios de deformação.
Em geral, são gerados segmentos de primeira e segunda ordem que coalescem rapidamente. Enquanto a falha da borda sudeste da bacia ortogonal é mais retilínea, com direção NE-SW, a falha de borda da bacia oblíqua tem direção E-W e mostra-se ligeiramente arqueada com concavidade para norte (Figura 18).

Nas extremidades das bacias, as respectivas falhas de borda têm mergulhos mais acentuados nos seus segmentos mais superiores e menores em profundidade (perfil AA', Figura 19). Esse fato se repete na porção central da bacia ortogonal, embora com mergulhos comparativamente mais elevados comparados àqueles da extremidade (perfil CC', Figura 19). A parte mais superior das falhas mostra intensidade variável do ângulo de mergulho entre as duas bacias.

Nos últimos estágios de deformação, enquanto a bacia ortogonal continuava o processo de abertura, grande parte das falhas da bacia oblíqua permaneceu inativa, resultando em uma parada na abertura dessa bacia. Dado a essa inatividade das falhas, essas estruturas não se propagaram até a superfície, ficando encobertas pela última camada de sedimentação sintectônica (Figura 18).

\section{Análise da geometria das falhas internas às bacias}

No interior da bacia ortogonal predominam falhas antitéticas à falha de borda, embora também ocorram pequenas falhas sintéticas nas proximidades da falha principal. Em geral, as falhas antitéticas cortam o pacote sedimentar e também afetam o embasamento cristalino. Na bacia ortogonal o número de falhas é ligeiramente superior àquele da bacia oblíqua.

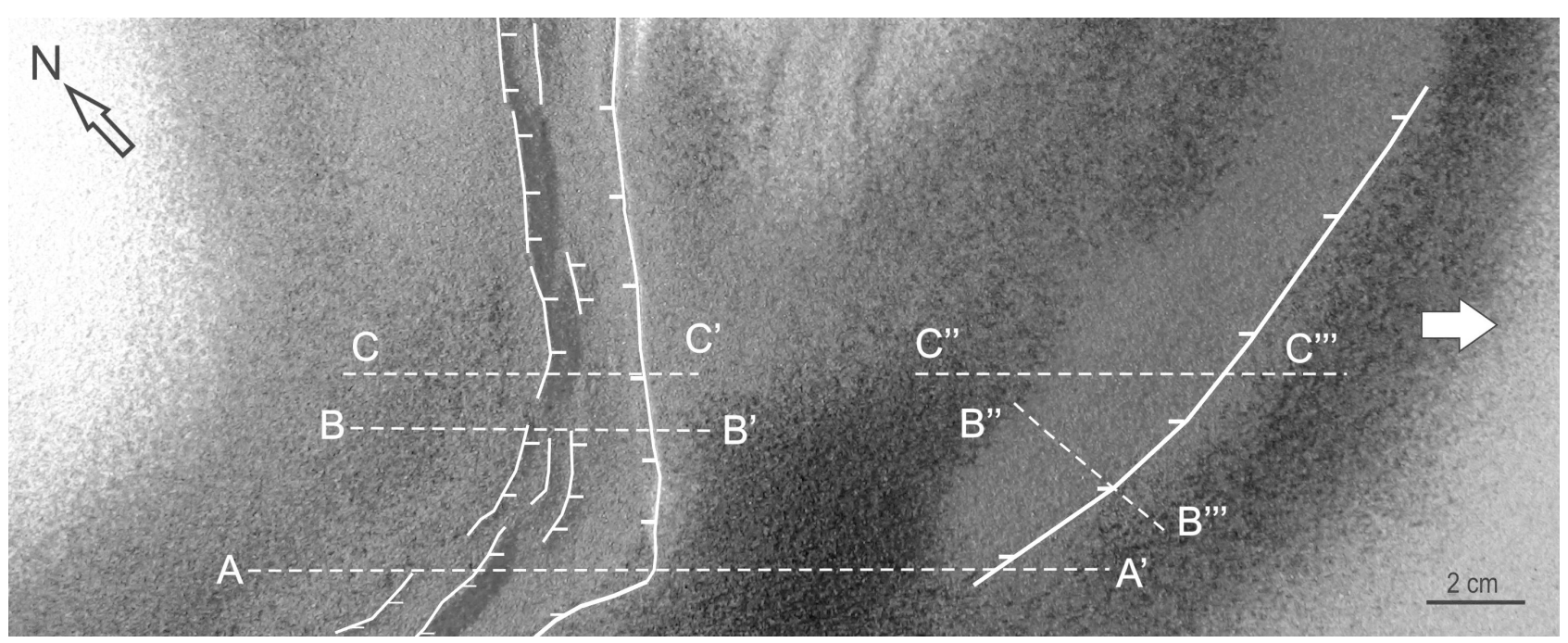

Figura 18. Fotografia do topo (superfície) do modelo $(\varepsilon=18 \%$ ), contemplando o desenvolvimento simultâneo de duas bacias, ortogonal (à esquerda na figura) e obliqua (à direita) à direção de distensão (marcada pela seta branca). Comparar o arranjo com a Figura 1. As linhas tracejadas representam a localização dos perfis ilustrados na Figura 20. 
Várias dessas falhas internas às bacias não se propagam até a superfície. Em superfície, essas falhas são mais bem desenvolvidas na bacia ortogonal, formando degraus e pequenas rampas de revezamento, principalmente nos extremos da bacia e no limite entre a porção ortogonal e a rampa oblíqua. Nesse local ocorre uma falha de transferência (não mostrada na Figura 18) que une a falha de borda da bacia ortogonal com uma das falhas internas na margem flexural da bacia oblíqua.

Em ambas as bacias, a primeira falha antitética importante define, junto com a falha de borda, o depocentro; na bacia ortogonal o depocentro é mais largo na extremidade sudoeste, onde a bacia faz uma inflexão para oeste (perfis AA', BB' e CC', Figura 20). Na bacia oblíqua o comportamento do depocentro é inverso, tornando-se mais largo em direção ao centro da bacia (perfís AA', B"B"' e C"C"', na Figura 20). Na extremidade sudoeste da bacia oblíqua, o perfil AA' não mostra a nucleação de falhas antitéticas e o depocentro é definido pelo mergulho das camadas sintectônicas em direção à falha de borda, em uma típica geometria em semigraben.

A intensidade do mergulho das falhas varia com a distância da falha de borda, havendo uma tendência à compartimentação em três domínios. Mais próximo às bordas falhadas, as falhas internas das bacias têm ângulo de mergulho de intensidade moderada (56-68 ); na porção intermediária os mergulhos diminuem, em comparação ao domínio anterior e, no domínio mais distal, as falhas exibem os mergulhos mais elevados $\left(65-75^{\circ}\right)$ (Figura 21). $\mathrm{Na}$ bacia ortogonal, as falhas do domínio proximal do perfil CC' mostram um comportamento anômalo, com intensa variação de mergulho. Não foi possível estabelecer se o mergulho mais baixo de algumas falhas é fruto do processo de rotação ou se essas falhas foram originalmente nucleadas com mergulhos mais baixos.

\section{COMPARAÇÃO ENTRE AS ESTRUTURAS EXPERIMENTAIS E A BACIA DO RIO DO PEIXE}

As bacias interiores do Nordeste brasileiro se desenvolveram contemporaneamente, em resposta à distensão NW-SE eocretácea que culminou com a abertura do Atlântico Sul, com nítido controle pelas estruturas (zonas de fraqueza) do embasamento. Os dados experimentais aqui apresentados são comparados com os dados disponíveis sobre a Bacia do Rio do Peixe, em especial os semigrabens de Brejo das Freiras e Sousa, com orientação ortogonal e oblíqua, respectivamente, à distensão NW-SE.

$\mathrm{O}$ arranjo arquitetural em subsuperfície da Bacia do Rio do Peixe é revelado por linhas sísmicas adquiridas pelo Projeto Bacias Interiores do Nordeste do Brasil (UFRN/Petrobras) e duas delas são ilustradas a seguir, para fins de comparação com os resultados da modelagem física. As linhas sísmicas 0295-2090 e 0295-2088 (Figuras 22A e 22B) têm orientação NW-SE, sendo que a primeira delas secciona as duas sub-bacias (Sousa e Brejo das Freiras), enquanto a segunda corta apenas o semigraben de Sousa. A linha 0295-2090 mostra os dois semigrabens controlados pelas respectivas falhas de borda, separados por um alto de embasamento (subaflorante)

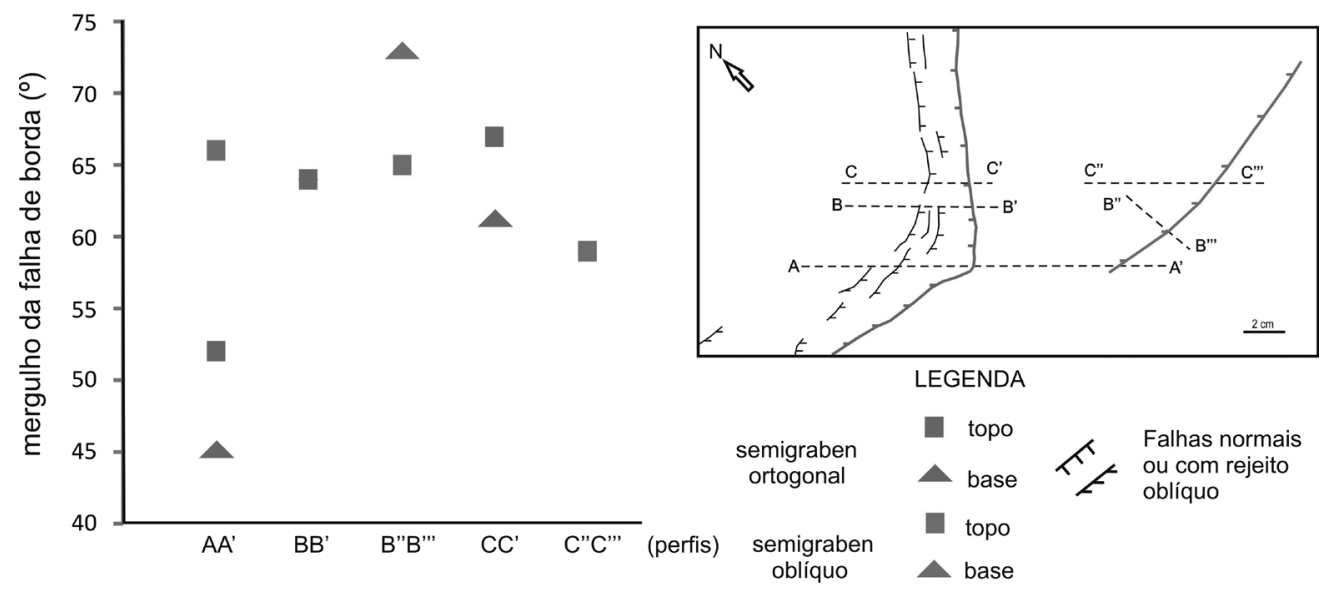

Figura 19. Relação do mergulho das falhas de borda, em superfície e subsuperfície, das bacias ortogonal e oblíqua. Nas suas extremidades oeste/sudoeste, nota-se que a parte superior da falha de borda da bacia oblíqua tem mergulho maior que aquela da bacia ortogonal (AA'), enquanto nas partes mais centrais (CC' e C"C'") ocorre o inverso. O inset mostra a localização dos perfis paralelos ou oblíquos à direção de distensão. 
C

$C^{\prime}$
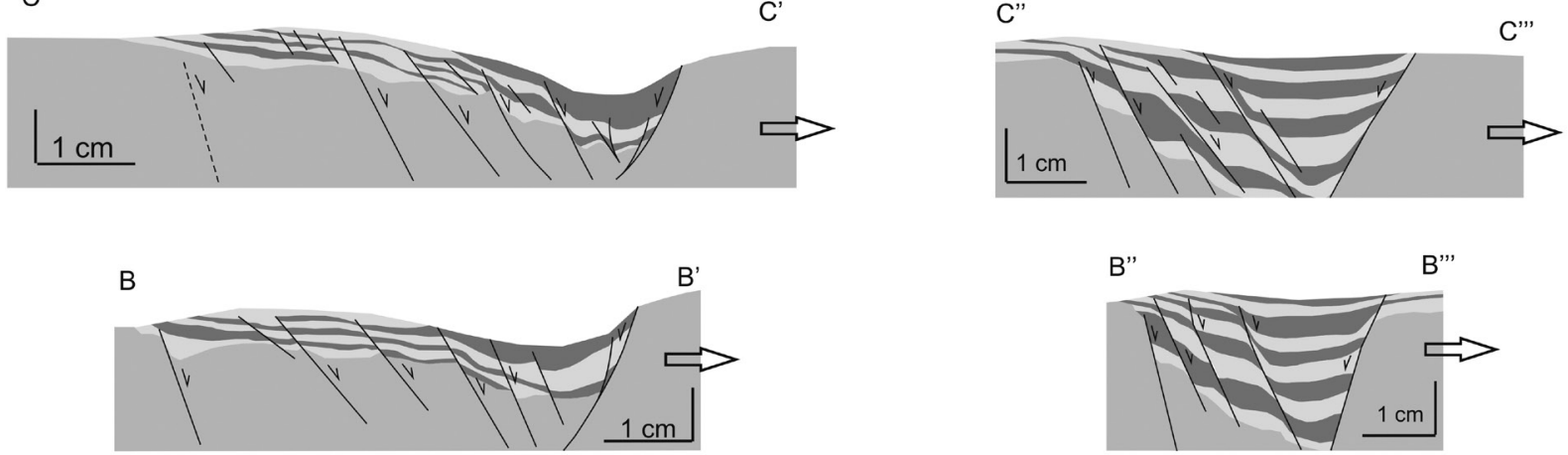

A

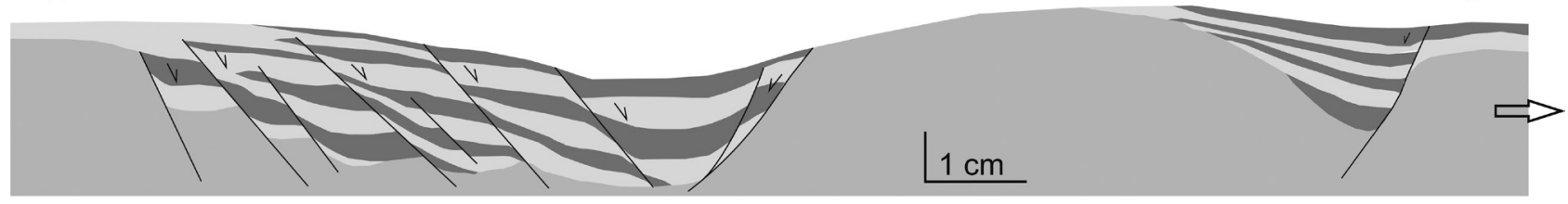

Legenda:

$\square$ embasamento

It falhas em perfil $\longrightarrow$ sentido da distensão

camadas sedimentares sintectônicas

Figura 20. Perfis transversais às bacias ortogonal (BB' e CC') e oblíqua (C"C"' e B"B"'). O perfil AA' secciona ambas as bacias (ver inset da Figura 19 para localização dos perfis). Nota-se uma variação na largura da região do depocentro, bem como no mergulho das falhas internas às bacias. Notar que algumas falhas não se propagam até a superfície.
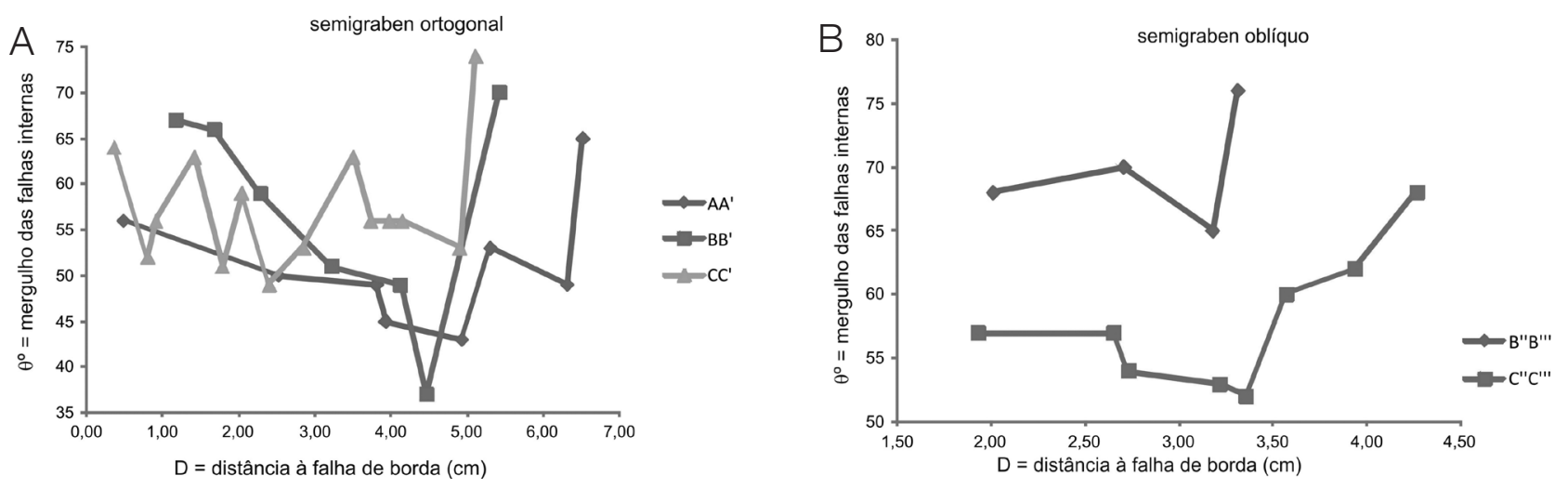

Figura 21. Ilustração gráfica da variação dos mergulhos das falhas internas às bacias, com a distância em relação à falha de borda; (A) bacia ortogonal e (B) bacia oblíqua. Notar que, no geral, as falhas mais distantes da falha de borda apresentam mergulho mais forte do que aquelas mais próximas.

entre elas (ver também Figura 22C). As falhas de borda apresentam um decréscimo no ângulo de mergulho com a profundidade, tendendo a uma geometria lístrica. A sub-bacia de Brejo das Freiras mostra a predominância de falhas sintéticas, da falha de borda à margem flexual, onde há, agora, uma concentração de falhas antitéticas de menor porte (Figura 22A). A margem falhada, porção
SE da sub-bacia, exibe a presença de um conjunto de três falhas que se unificam e se enraizam no embasamento como uma estrutura única. Na sub-bacia de Sousa, embora com um número de falhas internas bastante reduzido, ocorre o inverso, com pequenas falhas antitética mais próximas à falha de borda enquanto as sintéticas ocorrem mais próximas à margem flexural e a falha de borda é 


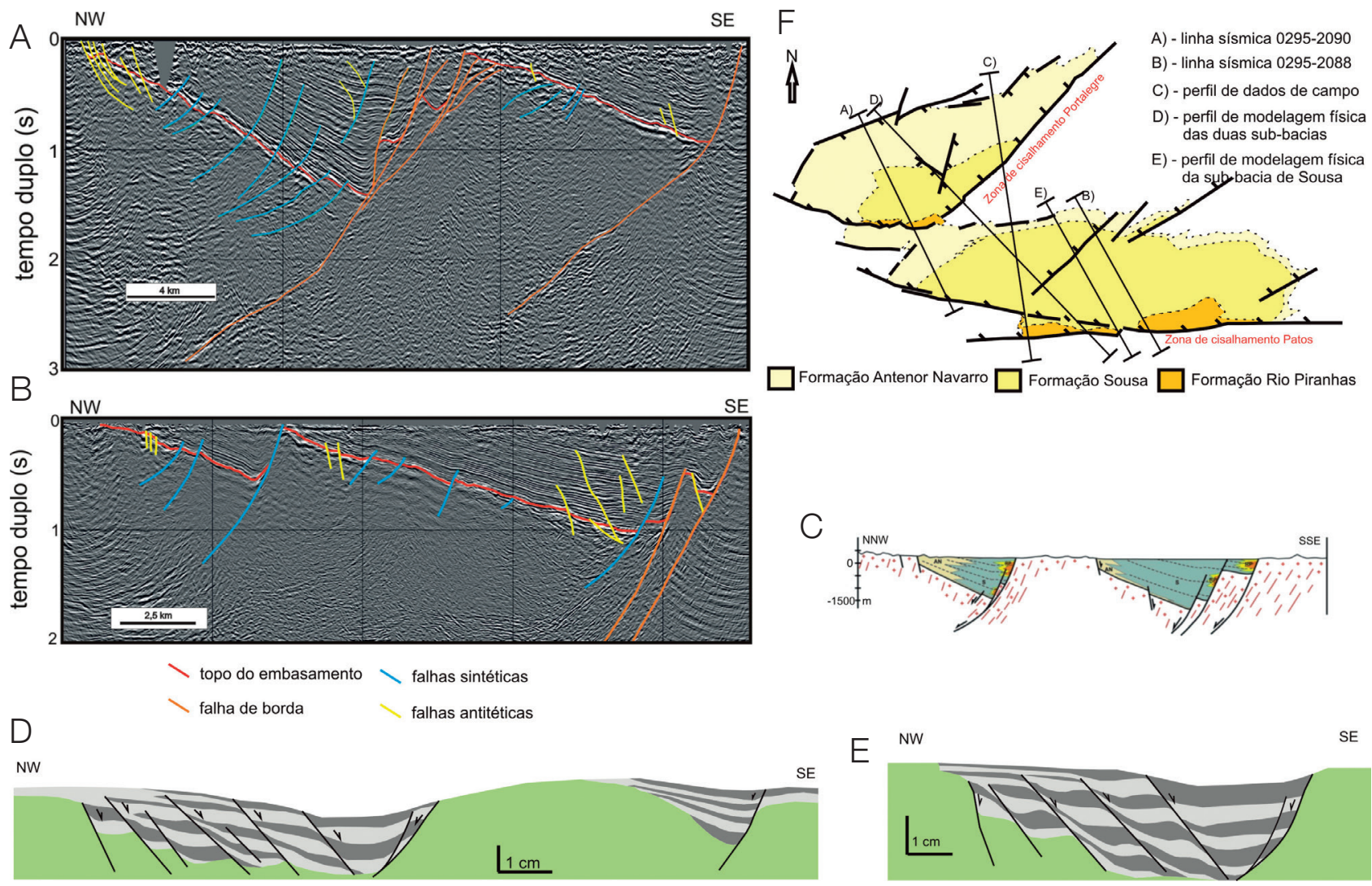

Figura 22. Ilustração das linhas sísmicas 0295-2090 (A) e 0295-2088 (B) da Bacia do Rio do Peixe; (C) perfil ilustrando o comportamento das duas sub-bacias com base nos dados estruturais de campo (Jardim de Sá e Campos, 2010); (D) seção obtida com a simulação de desenvolvimento simultâneo de uma bacia ortogonal e outra oblíqua à direção de distensão; (E) seção obtida da simulação da bacia oblíqua, mostrando a falha de borda ramificada com a formação de batente; (F) mapa da Bacia do Rio do Peixe (Jardim de Sá e Campos, 2010), com localização dos perfis sísmicos, de campo e da modelagem física. A interpretação estrutural das seções sísmicas foi feita pelo Alex F. Antunes (UFRN, trabalho inédito), com contribuição subordinada do primeiro autor deste trabalho.

uma estrutura única (Figura 22A). No que diz respeito às falhas internas, esse fato se repete na seção 0295-2088 que, como particularidade, exibe na borda falhada mais de uma falha, gerando batentes e, na extremidade NW da seção, uma falha sintética importante delimita um novo depocentro (Figura 22B). Em ambas as seções, várias das falhas internas à bacia (sintéticas e antitéticas) não atingem a superfície. A geometria lístrica das falhas de borda e um número relativamente pequeno de falhas interiores às bacias também é sugerido pelo perfil da Figura 22C, baseada em dados de campo (Jardim de Sá e Campos, 2010).

A modelagem em simultâneo das sub-bacias mostrou o desenvolvimento de uma sub-bacia mais ampla, cuja abertura foi ortogonal à direção de distensão, equivalente a sub-bacia de Brejo das Freiras, e outro semigraben de abertura mais restrita, oblíquo à direção de distensão, equivalente a sub-bacia de Sousa (Figura 22D). Os resultados experimentais exibem semelhanças e diferenças em relação ao análogo de campo. Como principais semelhanças destacam-se a geometria das falhas de borda, que apresentam geometrias lístricas, às vezes com o desenvolvimento de batentes ou patamares (Figuras 22D e 22E), podendo se mostrarem ramificadas, como observado nas seções sísmicas e pela interpretação dos dados de campo. São também características as dobras de propagação de falhas, formando estruturas sinclinais (ou em bacia) que permitem definir as regiões de depocentro. $\mathrm{O}$ depocentro da sub-bacia de Brejo das Freiras é mais profundo que aquele da sub-bacia de Sousa. A presença de falhas com desenvolvimento restrito às camadas mais inferiores das bacias também é um fato comum nos perfís da modelagem física (Figura 20), em consonância com a estruturação ilustrada nas seções sísmicas.

O principal contraste nos resultados obtidos relaciona-se ao expressivo desenvolvimento, na modelagem, de falhas antitéticas. Tomando como exemplo o semigraben de abertura ortogonal, observa-se a geração de uma série de falhas antitéticas na margem flexural, a exemplo do 
modelo natural; todavia, a continuação desse sistema de falhas em direção à borda falhada difere do modelo natural, que nessa região exibe várias falhas sintéticas (comparar as Figuras 22D e 22A). O número de falhas antitéticas desenvolvidas nos perfís das Figuras 9B e 16 é superior àquele visualizado nas seções sísmicas. As falhas sintéticas, pouco desenvolvidas nos experimentos, são mais comuns na Sub-bacia de Brejo das Freiras que na Sub-bacia de Sousa e são, em grande maioria, localizadas no embasamento, atingindo apenas as camadas mais basais das bacias (Figura 22A). Esse fato sugere a presença de descontinuidades menores no substrato da bacia, não consideradas na modelagem, que sofreram pequena reativação durante o processo de distensão.

\section{DISCUSSÕES E CONCLUSÕES}

Um dos principais aspectos a destacar na modelagem realizada é o desenvolvimento, no tempo e no espaço, das falhas que dão o contorno principal das bacias. A influência da trama pretérita (herdada do embasamento) na geometria e no desenvolvimento das bacias foi reproduzida com sucesso e assim confirmada. Quando as bacias ortogonal e oblíqua à direção de distensão foram geradas de forma independente, observou-se a conservação parcial da sua largura durante alguns incrementos deformacionais (Figura 11), que são interpretados como devido à transferência da deformação para uma nova falha mais interna ao semigraben, com as falhas mais antigas ficando encobertas pela sedimentação sintectônica (o monitoramento foi feito na superfície). Esse fato também sugere a migração, de NW para SE, dos depocentros dos semigrabens. Quando a geração dos semigrabens foi simultânea, verificou-se que a abertura de um semigraben interfere, de alguma forma, no desenvolvimento temporal e na velocidade/intensidade de abertura do outro. Em determinados momentos, um dos semigrabens respondia menos aos incrementos deformacionais, resultando em quiescência ou sensível retardo na sua abertura. Comparando os perfís GG' (Figura 9) e CC' (Figura 20), verifica-se que o semigraben ortogonal, quando desenvolvido simultaneamente com o oblíquo, apresenta-se mais largo e com o depocentro mais raso. No caso do semigraben oblíquo, o depocentro continua sendo mais raso para o desenvolvimento em simultâneo, mas sua largura é inferior àquela apresentada no caso de geração independente (cf. perfis C"C"' e CC' das Figuras 20 e 12, respectivamente). Esse fato sugere a partição da deformação entre os dois semigrabens, quando são geradas simultaneamente. Essa interpretação é reforçada pela variação na velocidade e no tempo de abertura das bacias, uma vez que ao longo do experimento o semigraben ortogonal abriu anteriormente ao oblíquo, mas ambas mostraram intervalos com menor deformação ao longo dos incrementos na distensão.

Algumas das falhas, atualmente mapeadas como estruturas contínuas, desenvolveram-se, segundo a modelagem, por meio da interligação de segmentos escalonados, geralmente formando rampas de revezamento (Figura 15), o que pode ter implicações na forma de aporte de material para a bacia. O monitoramento, em superfície, da evolução desses segmentos mostrou alternância de coalescência e nova segmentação (às vezes com direção ligeiramente diferente da precedente), implicando no fato de que essas falhas apresentam uma geometria não regular.

$\mathrm{O}$ não aparecimento na modelagem de algumas falhas internas à bacia, como as estruturas de direção NE na Subbacia de Sousa (Figuras 20B e 20F), sugere que as falhas naturais devem estar ligadas à reativação de uma estrutura antiga do embasamento da bacia, que não foi considerada na simulação.

O conhecimento da localização de depocentros, rampas de revezamento e geometria das falhas fornece subsídios para interpretações dos sítios e rotas mais adequadas à geração, migração e acumulação de hidrocarbonetos, mostrando que a modelagem pode ser uma ferramenta adicional à interpretação da evolução de bacias sedimentares e sua avaliação exploratória.

\section{AGRADECIMENTOS}

A.J.P.C.B. agradece a Agência Nacional do Petróleo (ANP), por meio do PRH-22, pela bolsa de mestrado no Programa de Pós-Graduação em Geodinâmica e Geofísica da Universidade Federal do Rio Grande do Norte (UFRN). Agradecemos também aos revisores anônimos que contribuíram para a melhoria da primeira versão desse artigo. O Laboratório de Modelagem Física do PPGG que conta com o apoio da rede de Geotectônica da PETROBRAS.

\section{REFERÊNCIAS}

Acocella, V., Faccenna, C., Funiciello, R., Rossetti, F. (1999). Sand-box modelling of basement-controlled transfer zones in extensional domains. Terra Nova, 11, 149-156.

Bonini, M., Souriot, T., Boccaletti, M., Brun, J. P. (1997). Successive orthogonal and oblique extension episodes in a rift zone: Laboratory experiments with application to the Ethiopian Rift. Tectonics, 16, 347-362. 
Clifton, A. E., Schlische, R. W., Withjack, M. O., Ackermann, R. V. (2000). Influence of rift obliquity on fault-population systematic: results of experimental clay models. Journal of Structural Geology, 22, 1491-1509.

Córdoba, V. C., Antunes, A. F., Jardim de Sá, E. F., Silva, A. N., Sousa, D. C., Lins, F. A. P. L. (2008). Análise estratigráfica e estrutural da Bacia do Rio do Peixe, Nordeste do Brasil: integração de dados a partir do levantamento sísmico pioneiro 0295_rio_do_peixe_2d. Boletim de Geociências da Petrobras, 16, 53-68.

Corti, G., Wijk, J. V., Cloetingh, S., Morley, C. K. (2007). Tectonic inheritance and continental rift architecture: Numerical and analogue models of the East African Rift system. Tectonics, 26(6), 1-13.

Dooley, T., McClay, K. (1997). Analogue modelling of pull-apart basins. AAPG Bulletin, 81, 1804-1826.

Françolin, J. B. L. (1992). Analyse structurale du bassin du Rio do Peixe (Brésil). Tese (Doutorado). Rennes: Centre Armoricaine d'étude Structurale des Socles - Université de Rennes.

Françolin, J. B. L., Cobbold, P. R., Szatmari, P. (1994). Faulting in the early cretaceous rio do peixe basin (NE brazil) and its significance for the opening of the atlantic. Journal of Structural Geology, 16, 647-666.

Gomes, C. J. S., Caldeira, J. N. M. (2011). As propriedades friccionais de areias de quartzo (natural e colorida): medidas efetuadas em experimentos físicosanalógicos e um ring-shear tester. Revista Escola de Minas, 64(3), 289-298.

Gutowski, J., Koyi, H. A. (2007). Influence of oblique strike-slip faults on the mesozoic evolution of the southeastern segment of the mid-polish trough. Basin Research, 19, 67-86.

Hall, S. R., Farber, D. L., Audin, L., Finkel, R. C. (2012). Recently active contractile deformation in the fore arc of southern Peru. Earth and Planetary Science Letters, 337$338,85-92$.

Henza, A., Withjack, M., Schlische, R. (2011). How do the properties of a pre-existing normal-fault population influence fault development during a subsequent phase of extension? Journal of Structural Geology, 33, 1312-1324.
Hubbert, M. K. (1937). Theory of scale models as applied to the study of geologic structures. Geological Society of America Bulletin, 48, 1459-1519.

Hus, R., Acocella, V., Funiciello, R., de Batist, M. (2005). Sandbox models of relay ramp structure and evolution. Journal of Structural Geology, 27, 459-473.

Jardim de Sá, E. F., Campos, S. (Coords.). (2010). Arquitetura e evolução tectono-estratigráfica das bacias interiores do nordeste, a norte do lineamento Pernambuco, Relatório inédito. Natal: Petrobras/Funpec/UFRN.

Lohrmann, J., Kukowski, N., Adam, J. (2003). The impact of analogue material properties on the geometry, kinematics and dynamics of convergent sand wedges. Journal of Structural Geology, 25, 1691-1711.

Matos, R. M. D. (1992). The northeast Brazilian rift system. Tectonics, 11, 766-791.

Matos, R. M. D. (1999). History of the northeast brazilian rift system: kinematic implication for the break-up between brazil and west africa. In: N. R. Cameron, R. H. Bate, V. S. Clure (Eds.), The oil and gas habitats of the south atlantic (v. 153, 55-73). Geological Society of London (Special. Publication).

McClay, K., Bonora, M. (2001). Analogue models of restraining stepovers in strike-slip fault systems. $A A P G$ Bulletin, 85(2), 233-260.

McClay, K. R. (1990). Extensional faults systems in sedimentary basins: a review of analogue studies. Marine and Petroleum Geology, 7, 206-233.

McClay, K. R., White, M. J. (1995). Analogue modeling of orthogonal and oblique rifting. Marine and Petroleum Geology, 12, 137-151.

Morley, C. K., Nelson, R. A., Patton, T. L., Munn, S. G. (1990). Transfer zones in the east african rift system and their relevance to hydrocarbon exploration in rifts. $A A P G$ Bulletin, 74, 1234-1253.

Morley, C. K., Haranya, C., Phoosongsee, W., Pongwapee, S., Kornsawan, A., Wonganan, N. (2004). Activation of rift oblique and parallel pre-existing fabrics during extension and their effect on deformation style: examples from the rifts of Thailand. Journal of Structural Geology, 26, 1803-1829.

Nelson, R. A., Patton, T. L., McClay, C. K. (1992). Riftsegment interaction and its relation to hydrocarbon exploration in continental rift systems. AAPG Bulletin, 76, 1153-1169. 
Nunes da Silva, A. (2009). Arquitetura, litofácies e evolução tectono-estratigráfica da bacia do rio do peixe, Nordeste do Brasil. Dissertação (Mestrado). Natal: Programa de PósGraduação Geodinâmica e Geofísica - UFRN.

Panien, M., Schreus, G., Pfiffner, A. (2006). Mechanical behavior of granular material used in analogue modeling: insights from grain characterization, ring-shear tests and analogue experiments. Journal of Structural Geology, $28,1710-1724$.

Ponte, F. C., Hashimoto, A. T., Dino, R. (Coords.) (1991). Geologia das bacias sedimentares mesozóicas do interior do nordeste do Brasil, Relatório inédito. Rio de Janeiro: Petrobras/CENPES/DIVEX/SEBIPE.
Ponte, F. C., Ponte Filho, F. C. (1996). Estrutura geológica e evolução tectônica da bacia do Araripe, Relatório interno. Recife: DNPM, $4^{\circ} / 10^{\circ}$ distritos regionais.

Schlische, R. W., Withjack, M., Olsen, P. E. (2002). Relative timing of camp, rifting, continental breakup and basin inversion: tectonic significance. American Geophysical Union Monograph, 136, 33-59.

Teixell, A., Koyi, H. A. (2003). Experimental and field study of the effects of lithological contrasts on thrustrelated deformation. Tectonics, 22(5), 1054.

Tron, V., Brun, J. P. (1991). Experiments on oblique rifting in brittle-ductile systems. Tectonophysics, 188, 71-84. 